- Review -

\title{
Current Status and Future Challenges of Weather Radar Polarimetry: Bridging the Gap between Radar Meteorology/Hydrology/Engineering and Numerical Weather Prediction
}

\author{
Guifu ZHANG*1, Vivek N. MAHALE ${ }^{2}$, Bryan J. PUTNAM ${ }^{1}$, Youcun QI ${ }^{1}$, Qing CAO ${ }^{3}$, Andrew D. BYRD ${ }^{1}$, \\ Petar BUKOVCIC ${ }^{1}$, Dusan S. ZRNIC ${ }^{4}$, Jidong GAO ${ }^{4}$, Ming XUE ${ }^{1}$, Youngsun JUNG ${ }^{1}$, Heather D. REEVES ${ }^{4}$, \\ Pamela L. HEINSELMAN ${ }^{4}$, Alexander RYZHKOV ${ }^{1}$, Robert D. PALMER ${ }^{1}$, Pengfei ZHANG ${ }^{1}$, Mark WEBER $^{1}$, \\ Greg M. MCFARQUHAR ${ }^{1}$, Berrien MOORE III ${ }^{1}$, Yan ZHANG ${ }^{1}$, Jian ZHANG ${ }^{4}$, J. VIVEKANANDAN ${ }^{5}$, \\ Yasser AL-RASHID ${ }^{6}$, Richard L. ICE ${ }^{7}$, Daniel S. BERKOWITZ ${ }^{7}$, Chong-chi TONG ${ }^{1}$, \\ Caleb FULTON ${ }^{1}$, and Richard J. DOVIAK ${ }^{4}$ \\ ${ }^{1}$ University of Oklahoma, Norman, OK 73072, USA \\ ${ }^{2}$ NOAA/National Weather Service, Norman, OK 73072, USA \\ ${ }^{3}$ Enterprise Electronics Corporation, Enterprise, AL 36330, USA \\ ${ }^{4}$ NOAA/National Severe Storms Laboratory, Norman, OK 73072, USA \\ ${ }^{5}$ National Center for Atmospheric Research, Boulder, CO 80307, USA \\ ${ }^{6}$ Raytheon Company, Waltham, MA 02451, USA \\ ${ }^{7}$ Radar Operations Center, Norman, OK 73072, USA
}

(Received 14 August 2018; revised 21 December 2018; accepted 1 February 2019)

\begin{abstract}
After decades of research and development, the WSR-88D (NEXRAD) network in the United States was upgraded with dual-polarization capability, providing polarimetric radar data (PRD) that have the potential to improve weather observations, quantification, forecasting, and warnings. The weather radar networks in China and other countries are also being upgraded with dual-polarization capability. Now, with radar polarimetry technology having matured, and PRD available both nationally and globally, it is important to understand the current status and future challenges and opportunities. The potential impact of PRD has been limited by their oftentimes subjective and empirical use. More importantly, the community has not begun to regularly derive from PRD the state parameters, such as water mixing ratios and number concentrations, used in numerical weather prediction (NWP) models.

In this review, we summarize the current status of weather radar polarimetry, discuss the issues and limitations of PRD usage, and explore potential approaches to more efficiently use PRD for quantitative precipitation estimation and forecasting based on statistical retrieval with physical constraints where prior information is used and observation error is included. This approach aligns the observation-based retrievals favored by the radar meteorology community with the model-based analysis of the NWP community. We also examine the challenges and opportunities of polarimetric phased array radar research and development for future weather observation.
\end{abstract}

Key words: weather radar polarimetry, radar meteorology, numerical weather prediction, data assimilation, microphysics parameterization, forward operator

Citation: Zhang, G. F., and Coauthors, 2019: Current status and future challenges of weather radar polarimetry: Bridging the gap between radar meteorology/hydrology/engineering and numerical weather prediction. Adv. Atmos. Sci., 36(6), 571-588, https://doi.org/10.1007/s00376-019-8172-4.

\section{Article Highlights:}

- The current status/limitations and future challenges/opportunities of weather radar polarimetry are reviewed.

- The gaps between the radar meteorology/hydrology/engineering and NWP communities are revealed, and possible approaches to bridge them discussed.

- New methods and technologies that advance weather radar polarimetry to meet future needs are explored.

\footnotetext{
* Corresponding author: Guifu ZHANG

Email: guzhang1@ou.edu
} 


\section{Introduction and motivation}

Radar is a very important tool in weather observations and forecasts, and there is an increasing need for faster data updates and more informative measurements to advance the atmospheric sciences, as stated by Bluestein et al. (2014). While faster data updates can be realized with phased array radar (PAR) technology, multi-parameter weather measurements can be made by radar polarimetry. Weather radar polarimetry aims to obtain more detailed weather information from radars with polarization diversity (Doviak and Zrnić, 1993; Bringi and Chandrasekar, 2001; Zhang, 2016). Through decades of research and development, radar polarimetry has matured and been implemented on the network of Weather Surveillance Radars-1988 Doppler in the United States (WSR-88D), also referred to as NEXRAD (Next Generation Radar) (Doviak et al., 2000). Doppler weather radars in China and other countries have also been, or are being, upgraded with dual-polarization capability. Polarimetric radar data (PRD) are now available nationally and globally. The dual-polarization upgrade is an important and imperative milestone in weather radar technology because the additional information it provides about the shape, composition, and phase of hydrometeors is much needed for further understanding, quantifying, and predicting weather.

A single-polarization Doppler radar can only measure the reflectivity factor (also called reflectivity: $Z$ or $Z_{\mathrm{H}}$ ), radial velocity $\left(v_{\mathrm{r}}\right)$, and spectrum width $\left(\sigma_{\mathrm{v}}\right.$ or $\left.\mathrm{SW}\right)$. The Doppler measurements of $v_{\mathrm{r}}$ and $\sigma_{\mathrm{v}}$ respectively represent the mean and standard deviation (including shear) of the radial velocity of scatterers, i.e., the dynamic motion. Only the reflectivity directly provides microphysics information, but this one measurement is obviously insufficient to fully characterize the complex cloud and precipitation microphysics. For example, cloud microphysics is normally represented in convective-scale numerical weather prediction (NWP) models not by the one observed parameter, $Z$, but by several to over a dozen state variables used in microphysics parameterization schemes. These variables include the water mixing ratios and number concentrations for the five or six hydrometeor species (cloud water, cloud ice, rain, snow, and hail/graupel) used in many double-moment or multi-moment schemes (e.g., Milbrandt and Yau, 2005a, b; Morrison et al., 2005, 2009). There can be ten times more unknowns if spectrum bin microphysics is used (Khain et al., 2015).

Because reflectivity alone cannot fully characterize cloud microphysics, efforts and attempts have been made to increase the number of independent radar measurements to better understand and characterize weather conditions through frequency/wavelength and/or polarization diversities. For example, the Global Precipitation Measurement core observatory carries the space-borne $\mathrm{Ku} / \mathrm{Ka}$-band Dual-frequency Precipitation Radar (https://pmm.nasa.gov/GPM/flight-project/ DPR), which was advanced from the Tropical Rainfall Measuring Mission single-frequency precipitation radar (Huffman et al., 2007). While a multi-frequency radar can provide more information, it is essentially multiple radars and therefore expensive to build (Eccles and Atlas, 1973; Gosset and Sauvageot, 1992). The data from a multi-frequency radar are also complicated to analyze. For ground-based remote sensing, radar polarimetry is both cost-effective and efficient in providing more microphysical information (Seliga and Bringi, 1976; Seliga et al., 1979; Zrnic and Aydin, 1992).

In addition to the single polarization radar measurements of $Z, v_{\mathrm{r}}$, and $\sigma_{\mathrm{v}}$, a polarimetric radar can produce: differential reflectivity $\left(Z_{\mathrm{DR}}\right)$ - the ratio of reflectivity between the horizontally and vertically polarized waves; the co-polar correlation coefficient $\left(\rho_{\mathrm{hv}}\right)$; the differential phase $\left(\Phi_{\mathrm{DP}}\right)$ and/or its range derivative - specific differential phase $\left(K_{\mathrm{DP}}\right)$; the linear depolarization ratio (LDR); and the correlation coefficients between co-polar and cross-polar signals $\left(\rho_{\mathrm{xh}}\right.$ and $\left.\rho_{\mathrm{XV}}\right)$. Radar polarimetry is normally implemented in one of two modes: (i) dual-polarization (simultaneous transmission and simultaneous reception: STSR) mode, or (ii) full-polarization (alternate transmission and simultaneous reception: ATSR) mode. For practical reasons, as stated in section 4 of Doviak et al. (2000), most operational weather radars, including WSR$88 \mathrm{D}$, use the dual-polarization STSR mode and produce PRD of $Z, v_{\mathrm{r}}, \sigma_{\mathrm{v}}, Z_{\mathrm{DR}}, \rho_{\mathrm{hv}}$, and $\Phi_{\mathrm{DP}} / K_{\mathrm{DP}}$. Nevertheless, these PRD contain information about hydrometeor size, shape, orientation, and phase/composition, allowing for better characterization of cloud and precipitation microphysics (e.g., Zrnic and Ryzhkov, 1999). PRD have enormous, but as yet not fully tapped, potential to improve severe weather detection and warnings, as well as quantitative precipitation estimation (QPE) and forecasting (QPF).

Currently, we use PRD in severe weather observation and detection, hydrometeor classification, winter precipitation applications, and QPE. In observational studies, certain polarimetric radar signatures, such as the $Z_{\mathrm{DR}}$ arc, $\rho_{\mathrm{hv}}$ ring, and $K_{\mathrm{DP}}$ foot are identified and connected to certain microphysical processes (Kumjian and Ryzhkov, 2008; Romine et al., 2008). In hydrometeor classification (HC), a set of PRD is used in a fuzzy logic classification algorithm whereby the membership function of a radar variable for a species is established based on experience, and then the membership values are combined to make a decision as to which class the set of PRD represents (Vivekanandan et al., 1999; Straka et al., 2000; Park et al., 2009; Chandrasekar et al., 2013; Dolan et al., 2013). The classification results are used to detect severe weather and to select radar estimators to improve QPE (Giangrande and Ryzhkov, 2008). These uses of PRD in severe weather observations and detection have utility in the weather forecasting community. For example, the Warning Decision Training Division of the U.S. National Weather Service (NWS) offers a Radar and Applications Course as the initial training on the use of the WSR-88D for severe weather operations (http://training.weather.gov/wdtd/courses/rac/). The application of PRD is a fundamental part of the course due to the recent upgrade of the WSR-88D network to dualpolarization. The course includes training on the following topics: base PRD, HC, the melting layer algorithm, QPE rainfall products, severe hail detection, supercell morphology, and the tornado debris signature (TDS), as well as winter 
weather applications.

The use of PRD can provide vital real-time information to forecasters, thus helping to improve severe weather detection and warnings, but many of the methods are oftentimes subjective and empirical, and have limitations in realizing the full potential of PRD. In QPE, deterministic power-law relations are used for rain estimation from PRD (Zhang et al., 2016; Chen et al., 2017), which may not be optimal. Also, uncertainties of radar-derived products have not been accurately quantified and provided together with the products. More importantly, the community has not begun to regularly derive from PRD the state parameters used in convective-scale highresolution NWP models, such as water mixing ratios and number concentration. The question is: How should we efficiently utilize PRD to improve severe weather detection, aviation weather services, QPE, and QPF?

Ideally, PRD should be used to determine cloud and precipitation physics state variables and to improve microphysical parameterization in NWP models, which in turn are expected to improve the accuracy of weather quantification and to shorten the spin-up time of the NWP model forecast. Unfortunately, this cannot be done easily for several reasons: (i) the number of independent pieces of information from PRD is limited and is usually less than the number of state variables that are used in NWP models in the case of multi-moment and/or multi-species microphysics, resulting in underdetermined problems; (ii) relationships between state variables and polarimetric radar variables are not linear, and sometimes they are not entirely known, especially for ice-phase and mixed-phase species; (iii) there are errors in radar measurements of PRD and in the forward operators that connect model state variables to the radar variables; (iv) there are large errors and uncertainty in convective-scale NWP model physics and parameterization when NWP model constraints are used in retrieval through data assimilation (DA), and these prevent the PRD from substantially contributing to the model initialization and prediction; and (v) there is a disconnect between the radar meteorology and NWP communities in their use of PRD.

Although it is difficult and challenging, the efficient use of PRD and advancing radar technology for severe weather detection and warnings, QPE, and QPF, are still the main goals, which is the motivation behind the writing of this article. Specifically, we discuss and explore the following issues:

- The limitations of current PRD usage;

- The gaps between the radar meteorology/hydrology and NWP communities;

- The difficulty in assimilating PRD into NWP models;

- The development status of new radar technology and PAR polarimetry, to meet future needs.

Only once these shortcomings are realized and these challenges tackled can the optimal usage of PRD and efficient advancement of radar technology be achieved. The rest of this paper is organized as follows:

Section 2 shows examples of PRD and PRD usages/ products from WSR-88D. The issues and limitations of current PRD usage and the gaps between the radar meteorology and the NWP communities are discussed in section 3. Section 4 suggests a unified statistical approach to using PRD. An example of an NWP model-based analysis of PRD is shown in section 5. Section 6 discusses the status and challenges of research and development of polarimetric PAR technology. The paper concludes with a summary in section 7 .

\section{Current status of PRD usage}

After the dual-polarization upgrade completed in 2013, archived PRD from WSR-88D became available at NOAA's National Centers for Environmental Information (https:// www.ncdc.noaa.gov/nexradinv/index.jsp) in level II and level III format, which is summarized in Fig. 1. Level II data (left column) are base data estimated from pulsed radar signals, from which level III data/products are derived. The dashed boxes are the single polarization radar data and their derived products, and the solid boxes are for dual-polarization data and PRD-derived products. Compared with that over a dozen of single polarization products (middle column), the PRDderived products (right) are still very limited—only three, indicating future challenges exist and opportunities are to be explored. In this section, we discuss the current usage of PRD for weather observation, $\mathrm{HC}$, and QPE.

\subsection{PRD for weather observation and forecasting}

As shown in the left column of Fig. 1, WSR-88D level II data contain six variables, consisting of three existing single-polarization variables $\left(Z, v_{\mathrm{r}}, \sigma_{\mathrm{v}}\right)$ and three added dualpolarization variables $\left(Z_{\mathrm{DR}}, \rho_{\mathrm{hv}}\right.$, and $\left.\Phi_{\mathrm{DP}}\right)$, which contain a wealth of information about cloud and precipitation microphysics.

Each dual-polarization variable has specific properties/characteristics with regard to different weather or nonweather radar echoes, and, together with $Z$, they reveal the microphysical properties of clouds and precipitation. $Z_{\mathrm{DR}}$ is a measure of the reflectivity weighted shape of the scatterers and tends to increase for more oblate scatterers (within the Rayleigh regime). $\rho_{\mathrm{hv}}$ represents the similarity between the horizontal and vertical polarization signals, and it is reduced when there is increased randomness and diversity between the horizontally and vertically polarized backscattered waves, especially for non-Rayleigh scattering. Finally, $\Phi_{\mathrm{DP}}$ is the difference in phase shift between horizontally and vertically polarized waves, including both differential scattering phase $(\delta)$ and differential propagation phase $\left(\phi_{\mathrm{DP}}\right) . \phi_{\mathrm{DP}}$ increases rapidly for heavy rain because the horizontally polarized wave propagates slower than the vertically polarized wave, as its polarization is in the direction of the larger dimension of oblate particles.

When used in conjunction with ground-based observations and storm reports (when available), their understanding of the storm morphology, and the near-storm environment (i.e., mesoanalysis), meteorologists who serve as warning forecasters at the U.S. NWS use radar data to make warning decisions on whether a thunderstorm is capable of pro- 


\section{WSR-88D Data and Derived Products}

\begin{tabular}{|c|c|c|}
\hline Level II data & Level III & ata \\
\hline $\begin{array}{l}\text { Single-pol Base Data: } \\
\text { - Reflectivity }\left(\mathrm{Z} / \mathrm{Z}_{\mathrm{H}}\right) \\
\text { - Velocity }\left(\mathrm{V}_{\mathrm{r}}\right) \\
\text { - Spectrum Width } \\
\left(\sigma_{\mathrm{V}} / \mathrm{SW}\right)\end{array}$ & \multirow{3}{*}{$\begin{array}{l}\text { Reflectivity Derived } \\
\text { Products: } \\
\text { - Storm Identification \& } \\
\text { - Hracking } \\
\text { - Hail Index } \\
\text { - Vertipitation Prepropossing } \\
\text { - VIL) } \\
\text { - Composite Reflectivity } \\
\text { - Enhanced Echo Tops } \\
\text { - VAD Wind Profile } \\
\text { - Mesocyclone Detection } \\
\text { - Tornado Vortex Signatures } \\
\text { (TVS) }\end{array}$} & \multirow{2}{*}{\begin{tabular}{|l} 
PRD Derived \\
Products: \\
- Melting Layer \\
Detection \\
- Hydrometeor \\
Classification \\
(HC) \\
- Quantitative \\
Precipitation \\
Estimation \\
(QPE)
\end{tabular}} \\
\hline $\begin{array}{l}\text { Dual-pol Base Data: } \\
\text { - Differential } \\
\quad \text { Reflectivity }\left(Z_{D R}\right) \\
\text { - Correlation } \\
\text { Coefficient }\left(\rho_{\mathrm{hv}} / \mathrm{CC}\right)\end{array}$ & & \\
\hline $\begin{array}{l}\text { Ditferential phase } \\
\left(\phi_{\mathrm{DP}}\right)\end{array}$ & & \\
\hline
\end{tabular}

Fig. 1. WSR-88D data and their derived products after the dual-polarization upgrade. The data and products in the dashed boxes are for single polarization.

ducing severe weather $\left(\geqslant 26 \mathrm{~m} \mathrm{~s}^{-1}\right.$ winds and/or $\geqslant 2.54 \mathrm{~cm}$ hail) and/or a tornado. If a forecaster has enough confidence for severe weather and/or a tornado, the forecaster can issue a severe thunderstorm warning or tornado warning with the potential hazards (i.e., estimated maximum hail size, estimated maximum wind speed, and tornado damage threat). The addition of PRD gives forecasters additional information on the storm morphology, which can assist in warning decision-making.

An example from a warm-season event is used to demonstrate the PRD and its utility in weather observations and warnings. Figure 2 shows the plan position indicator (PPI) images of these data at an elevation of $1.3^{\circ}$ for a tornadic supercell event observed by the S-band polarimetric WSR88D (KFDR) radar in southwest Oklahoma at 2243 UTC 16 May 2015. Six PPI images represent the polarimetric Doppler weather radar measurements of $Z$ (Fig. 2a), $v_{\mathrm{r}}$ (Fig. 2b), and $\sigma_{\mathrm{v}}$ (Fig. 2c), as well as the added dual-polarization measurements of $Z_{\mathrm{DR}}$ (Fig. 2d), $\rho_{\mathrm{hv}}$ (Fig. 2e), and $\Phi_{\mathrm{DP}}$ (Fig. 2f). The red polygon is a tornado warning that was issued by NWS Norman, Oklahoma, Weather Forecast Office (WFO).

The storm is a classic supercell with a hook echo. At the tip of the hook (on the southwest flank of the storm), a mesocyclone is sampled by the radar, as indicated by a cyclonic velocity couplet. On the forward flank of the supercell, along with the reflectivity gradient on the southern edge, there is an increase in $Z_{\mathrm{DR}}$. This feature is known as a $Z_{\mathrm{DR}}$ arc, which occurs due to size-sorting in a supercell that occurs because of vertical wind shear (Kumjian and Ryzhkov, 2008). Northwest of the $Z_{\mathrm{DR}}$ arc, $\Phi_{\mathrm{DP}}$ increases markedly with range. This is due to very heavy rainfall in the forward flank downdraft (FFD) of the supercell. Immediately to the west-northwest of the hook, there is a reduction in $Z_{\mathrm{DR}}$ and $\rho_{\mathrm{hv}}$ within an area of high reflectivity. These measurements are likely due to the presence of hail mixing with rain. The final signature to note is a local minimum in the $\rho_{\mathrm{hv}}$ and $Z_{\mathrm{DR}}$ at the center of the velocity couplet, which is coincident with reflectivity $>40 \mathrm{dBZ}$. The low $\rho_{\mathrm{hv}}$ and $Z_{\mathrm{DR}}$ indicates the presence of non-meteorological targets. This signature, known as a TDS, exists due to debris being lofted by a tornado (Ryzhkov et al., 2005; Kumjian and Ryzhkov, 2008; Kumjian, 2013; Van Den Broeke and Jauernic, 2014). In this event, the presence of a TDS resulted in the NWS Norman WFO issuing a severe weather statement (i.e., updated tornado warning) where the hazard in the warning became "damaging tornado" and the source for the warning became "radar confirmed tornado." In this example, the PRD had an important role in warning decision-making by providing information that heightened the wording of the warning statement.

Though the previous example is a warm-season event, PRD have applications in the cold season too (Zhang et al., 2011; Andrić et al., 2013), including melting-layer detection and precipitation type transition zones (Brandes and Ikeda, 2004; Giangrande et al., 2008; Bukovčić et al., 2017), and in the study of ice microphysical processes (Griffin et al., 2018). Polarimetric radars have also been successfully used in the study of tropical meteorology (Rauber et al., 2007; May et al., 2008; Brown et al., 2016; Didlake and Kumjian, 2017).

\subsection{PRD products}

\subsection{1. $H C$}

While it is informative to look at the individual polarimetric variable images, it is more scientific, rigorous, and efficient to systematically and automatically use the PRD for accurate weather measurements and forecasting (Straka and Zrnić, 1993; Straka, 1996). The first such use was in hydrometeor (or echo) classification based on a fuzzy logic algorithm (Vivekanandan et al., 1999; Liu and Chandrasekar, 2000). An updated version of the $\mathrm{HC}$ algorithm (HCA) described 


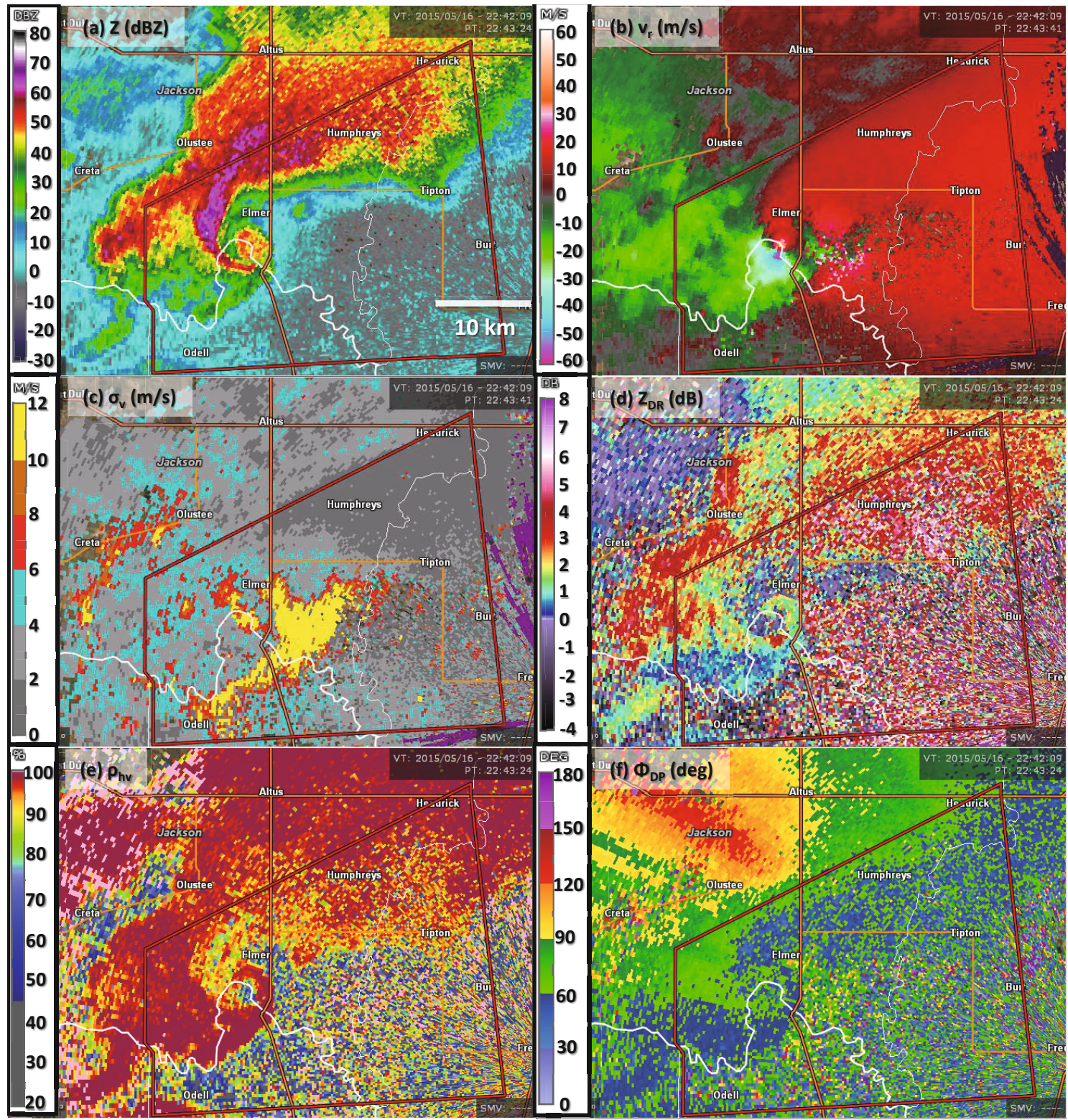

Fig. 2. Polarimetric variables at the S-band radar KFDR for a supercell observed in southwest Oklahoma, USA, at 2243 UTC 16 May 2015: (a) reflectivity $(Z)$; (b) radial velocity $\left(v_{\mathrm{r}}\right)$; (c) spectrum width $\left(\sigma_{\mathrm{v}}\right)$; (d) differential reflectivity $\left(Z_{\mathrm{DR}}\right)$; (e) copolar correlation coefficient $\left(\rho_{\mathrm{hv}}\right)$; and (f) differential phase $\left(\Phi_{\mathrm{DP}}\right)$. The radar (not shown) is located southeast of the supercell. The white lines are county or state borders, and the orange and brown lines are roadways. Plotted using GR2Analyst software.

by Park et al. (2009) is implemented on the WSR-88D. Its input parameters are $Z, Z_{\mathrm{DR}}, \rho_{\mathrm{hv}}$, the logarithm of $K_{\mathrm{DP}}$, the standard deviation of $Z$, and the standard deviation of $\Phi_{\mathrm{DP}}$. Its output is ten classes of radar returns (light/moderate rain, heavy rain, rain/hail mix, big drops, dry snow, wet snow, crystals, graupel, biological, and ground clutter) plus "no echo" and "unknown", and the elevation-based HC is available as one of the WSR-88D level III products. A hybrid version of the HC product (called HHC), derived from the elevation-based $\mathrm{HC}$, is created for the dual polarization QPE. Recent modifications to the HCA include a hail size discrimination for the rain/hail mix category (Ryzhkov et al., 2013a, b; Ortega et al., 2016): large hail (at least $2.54 \mathrm{~cm}$ in diameter but less than $5.08 \mathrm{~cm}$ ) and giant hail (greater than or equal to $5.08 \mathrm{~cm}$ ). Using the graupel classification from the HCA as a primary input, the WSR-88D algorithm suite now also includes an icing hazard level product that is used by the Federal Aviation Administration to detect regions of icing aloft.

Figure 3a shows the HCA output from the KFDR radar for the event depicted in Fig. 2. Although it is not easy to verify the HCA output by comparisons with in-situ measurements, the results of the classification in Fig. 3a fit the accepted microphysical understanding of a severe super-cell storm. As expected, the area of high reflectivity with reduced $Z_{\mathrm{DR}}$ and $\rho_{\mathrm{hv}}$ is classified as rain and hail (HA: red). Heavy rain (HR: dark green) is identified in the FFD region, consis- 


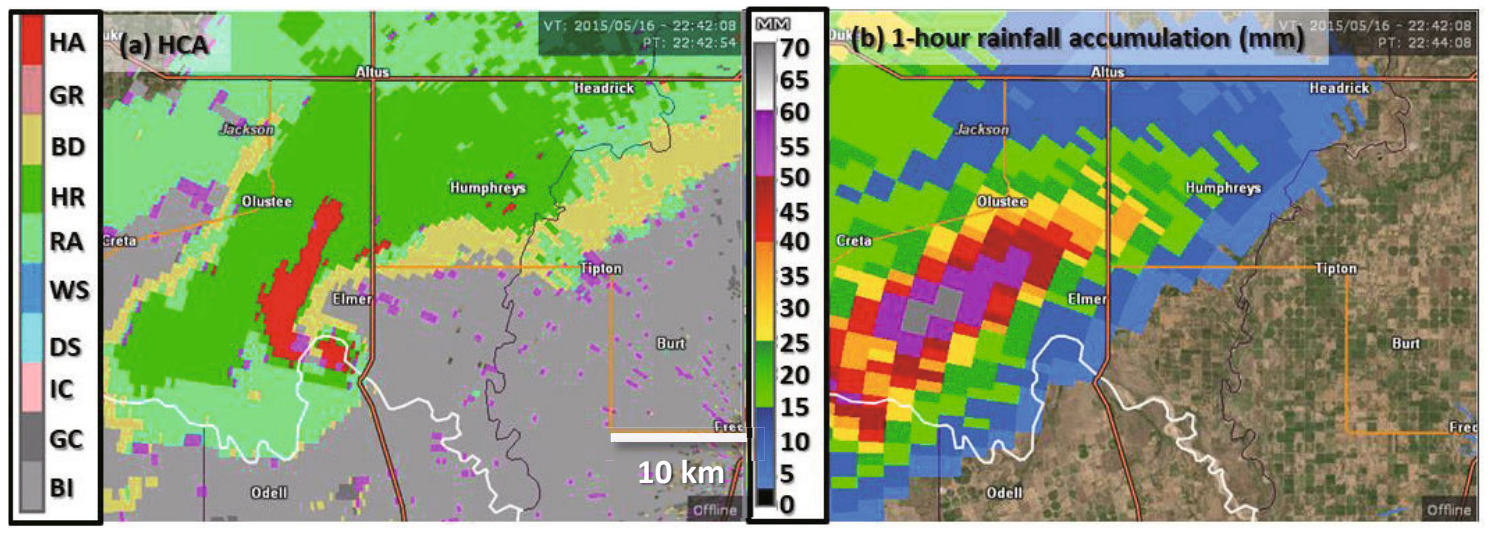

Fig. 3. (a) Hydrometeor classification product generated from the NSSL hydrometeor classification algorithm at 2243 UTC 16 May 2015, and (b) dual-polarization radar estimated hourly rainfall accumulation. The radar is located southeast of the supercell (not shown). The white lines are county or state borders, and the orange and brown lines are roadways. These were plotted using GRLvel3 software. The echo class notations are: biological scatterers (BI); ground clutter (GC); ice crystals (IC); dry snow (DS); wet snow (WS); light/moderate rain (RA); heavy rain (HR); big drops (BD); graupel (GR); and rain and hail (HA). Purple areas represent unknown classification.

tent with the rapid increase in $\Phi_{\mathrm{DP}}$ noted in the previous subsection. Light and moderate rain (RA: light green) are identified at the southwest edge of the storm. The leading side of the storm is classified as big drops (BD: brown), which is reasonable due to size sorting. It is also reasonable to see biological scatterers (BI: light gray) identified ahead of the storm near the radar where insects normally appear.

However, a couple of issues presently exist and are being addressed. The melting layer with high reflectivity has often been misclassified as graupel and big drops. A recent version of HCA classifies more hydrometeors within the melting layer as wet snow. Also, the current melting layer detection algorithm (MLDA) does not perform well with cool-season precipitation where the melting layer is close to the ground and where there are mixed-phase hydrometeors. An improved MLDA that allows for microphysically based variations in the heights of the top and bottom of the melting layer is under development (Reeves, 2016). It uses several inputs from a rapid refresh forecast model. A recent advancement in HCA with PRD is to use an objective approach to derive statistical relations based on cluster analysis (Wen et al., 2015, 2016).

\subsection{2. $Q P E$}

Whereas HCA is very successful in systematically utilizing PRD for revealing cloud and precipitation microphysics, it is qualitative and empirical rather than quantitative. One of the main motivations to develop weather radar polarimetry was to improve QPE with polarimetric measurements, such as $Z_{\mathrm{DR}}$ (Seliga and Bringi, 1976; Seliga et al., 1979; Ulbrich and Atlas, 1984) and $K_{\mathrm{DP}}$ (Sachidananda and Zrnić, 1987; Ryzhkov and Zrnić, 1996), because polarimetric measurements depend on the shape of hydrometeors, and raindrop shape is monotonically related to the drop size. Hence, radar rain estimators with different combinations of $Z, Z_{\mathrm{DR}}$, and $K_{\mathrm{DP}}$ were developed using simulated or measured rain drop size distributions (DSDs) and electromagnetic scattering models (Jameson, 1991; Vivekanandan et al., 1991; Ryzhkov and Zrnić, 1995). The improvement of QPE with PRD has been demonstrated with real data in a subtropical environment (Brandes et al., 2002), in the Southern Great Plains region (Giangrande and Ryzhkov, 2008), and in a tropical region (May et al., 1999; Chang et al., 2009), as well as in Europe (Figueras i Ventura and Tabary, 2013). It is generally accepted that the estimation error decreases from $30 \%$ to $40 \%$ uncertainty for a single polarization reflectivity to about $15 \%$ error for polarimetric measurements (Brandes et al., 2002).

A synthetic polarimetric radar rain estimator that combines different estimators based on HCA results was initially adapted by the dual-polarization WSR-88D to produce level III QPE products (Giangrande and Ryzhkov, 2008). The dual-polarization QPE products are currently generated based on the five primary rain estimators:

$$
\begin{aligned}
R(Z) & =0.017 Z^{0.714}, \quad\left(Z=300 R^{1.4}\right) ; \\
R\left(K_{\mathrm{DP}}\right) & =44\left|K_{\mathrm{DP}}\right|^{0.822} \operatorname{sign}\left(K_{\mathrm{DP}}\right) ; \\
R\left(Z, Z_{\mathrm{dr}}\right) & =0.0142 Z^{0.77} Z_{\mathrm{dr}}^{-1.67} ; \\
R\left(Z, Z_{\mathrm{dr}}\right) & =0.0067 Z^{0.927} Z_{\mathrm{dr}}^{-3.43} ; \\
R\left(K_{\mathrm{DP}}\right) & =27\left|K_{\mathrm{DP}}\right|^{0.822} \operatorname{sign}\left(K_{\mathrm{DP}}\right) .
\end{aligned}
$$

Here, $\operatorname{sign}\left(K_{\mathrm{DP}}\right)$ allows for negative $K_{\mathrm{DP}}$ values and both $Z$ and $Z_{\mathrm{dr}}$ are in linear units instead of logarithmic values for $Z / Z_{\mathrm{H}}$ and $Z_{\mathrm{DR}}$. The three rain estimators are used/chosen based on HCA results. For example, if the echo is classified as light to moderate rain, Eq. (3) or Eq. (4) of $R\left(Z, Z_{\mathrm{dr}}\right)$ is used to estimate the rain rate, depending whether an operator chooses a "continental" or "stratiform/tropical" relationship, respectively; if the echo is classified as heavy rain, Eq. (2) of $R\left(K_{\mathrm{DP}}\right)$ is used; if the echo is classified as hail-rain mixture, Eq. (5) of $R\left(K_{\mathrm{DP}}\right)$ is used to mitigate hail contamination. Most classifications within and above the melting layer use Eq. (1), usually with a multiplier of $R(Z)$, such as $0.6 \times R(Z)$ for wet snow. Figure $3 \mathrm{~b}$ shows the dual-polarization radar-based QPE result that has much less contamination from anoma- 
lous propagation clutter and biological scatterers. The dualpolarization QPE, based on $Z, Z_{\mathrm{dr}}$, and $K_{\mathrm{DP}}$, provided improved precipitation estimates over the previous single polarization QPE in warm-season events where the freezing level was high. However, it has relatively large random errors due to its sensitivity to errors in $Z_{\mathrm{dr}}$, which are significant at times. The dual-polarization QPE also suffers from discontinuities and some biases near the melting layer. The $R\left(K_{\mathrm{DP}}\right)$ estimator can produce a negative rain rate, which is physically impossible, if $K_{\mathrm{DP}}$ is estimated from $\Phi_{\mathrm{DP}}$ using a least-squares fit, as is currently used for WSR-88D. A recent advancement is to improve $K_{\mathrm{DP}}$ estimation for better QPE by using a hybrid method of combining linear programming (also called linear optimization) and physical constraints (Giangrande et al., 2013, Huang et al., 2017), which yields the best match with observed $\Phi_{\mathrm{DP}}$ while ensuring positive $K_{\mathrm{DP}}$ estimates. The latest developments also include the use of specific attenuation for rainfall estimation (Ryzhkov et al., 2014; Zhang et al., 2017). There is also interest in using X-band polarimetric radar networks to improve QPE and low-level coverage (Chen et al., 2015).

\section{Issues with current PRD usage}

As discussed in the last section, it is informative and intuitive to observe polarimetric radar signatures for detection and warning of severe storms and aviation hazards, exciting to see PRD HC results reveal cloud and precipitation microphysics, and satisfactory to improve QPE with PRD. PRD can serve the community better and its potential can be better realized if the issues and limitations of the current usage of PRD are acknowledged and resolved. These issues are as follows:

As noted in the introduction, the independent information of PRD is still limited, and the relative errors of polarimetric measurements can be large. The number of independent pieces of information varies depending on the hydrometeor species: $\sim 1$ for drizzle or dry snow; 3-4 for melting snow or hail. The relative error of $Z_{\mathrm{DR}}$ and $K_{\mathrm{DP}}$ can be $100 \%$ for light rain due to the small intrinsic values. Furthermore, system uncertainty and bias affect the accuracy of polarimetric measurements (Zrnic et al., 2006). Even with a well-calibrated radar system, the overall uncertainty of the bias/error has historically been greater than the required tolerance (e.g., $0.1 \mathrm{~dB}$ bias for $Z_{\mathrm{DR}}$ ), limiting the quantitative usage of PRD (Ice et al., 2014).

Severe weather (such as hail and tornado)-related observation studies with PRD have been highly subjective and empirical. It is difficult to automatically use and expand the subjectively decided polarimetric signatures/knowledge for operational usage in severe weather detection, prediction, and warning. It would be beneficial to warning forecasters if there are products that utilize PRD to better quantify potential hazards, such as maximum hail size or tornado damage threat. As shown in Fig. 1, there is no severe weather detection product that has been generated in WSR-88D level-III PRD products (with the exception of the hail size discriminator in the latest HCA), compared with many reflectivity-derived, velocity-derived products. This is because not all the weather science has been fully understood, and rigorous relations between weather states and PRD have not been fully established. Therefore, further research and development needs to be done.

Classifications have been successful, but are still qualitative, and some severe weather conditions (e.g., TDS) are not in the HCA output. Also, a dominant contributor to PRD may not necessarily be the main contributor to microphysics states/processes. For example, a hydrometeor class determined from PRD may not necessarily have the highest water mixing ratio or evaporation rate if other classes exist in the radar resolution volume. This is because radar measurements are mainly determined by higher DSD moments (e.g., approximately 6th moment for reflectivity) dominated by a few large particles rather than the large number of small drops which have important effects on microphysical processes, thermodynamics, and storm development.

Power-law-type polarimetric radar rain estimators [e.g., Eqs. (1)-(5)] may not be optimal, because it is difficult to use prior information and measurement errors in rain estimation once a power-law estimator is chosen. True relations (if they exist at all) between rain rate and radar variables may not necessarily be in power-law form. For example, if rain DSDs are exponentially or gamma distributed, the analytically derived $R\left(Z, Z_{\mathrm{dr}}\right)$ is not in power-law form [see Zhang, 2016, Eq. (6.26)]. The power-law form was used for simplicity because it becomes a linear function after taking the logarithm of both sides; this makes for an easy fit to data. Even if the functional form is acceptable, the least-squares fitting with a constant weight for all data points is optimal only if the errors are Gaussian-distributed in the logarithm domain. Otherwise, least-squares fitting does not yield the minimal error. Furthermore, a minimal error in the logarithm domain does not necessarily yield a minimal error in the linear domain for rain estimation. Also, the HC-based QPE can cause discontinuity in rain estimation because the chosen estimator switches relations discretely according to subjectively determined conditions, even though the underlying microphysical condition has evolved only continuously. Furthermore, model errors, measurement errors of the involved radar variables and rain rate, and data sampling/collection issues are not considered in the formulation and fitting procedure, yielding uncertainty in QPE results.

Another issue-likely the most important-is the difficulty involved in using the current PRD or PRD products to improve NWP. The difficulty comes from: (i) the large variety/uncertainty in storm-scale NWP models and model parameterization (discussed further in section 5); and (ii) a disconnect between model basic state variables (e.g., water mixing ratio and number concentration) and polarimetric variables. Efforts have been made to develop PRD simulators (i.e., forward operators) to connect model variables with PRD variables through cloud/precipitation microphysics rooted in drop/particle size distribution (DSD/PSD), $N(D)$, 
and other physical and statistical properties such as shape, orientation, and composition reflected in scattering matrix elements, as in Doviak and Zrnić (1993, section 8.5.2.2), Bringi and Chandrasekar (2001, section 3.10.1) and Zhang (2016, section 4.2.6). Based on scattering calculations with the $T$-matrix method (Waterman, 1965; Vivekanandan et al., 1991), Jung et al. (2008a, 2010), Pfeifer et al. (2008), and Ryzhkov et al. (2011) all developed different forward operators, and were able to simulate realistic PRD signatures from NWP model output. The computer code in Fortran language for PRD operators is posted on the University of Oklahoma website (http://arps.ou.edu/downloadpyDualPol.html). There is also a freely available Cloud Resolving Model Radar Simulator (http://radarscience.weebly.com/radar-simulators.html) developed by a group of scientists from Stony Brook University and Brookhaven National Laboratory. Colorado State University and NASA's Goddard Space Flight Center also developed the Polarimetric Radar Retrieval and Instrument Simulator (https://cloud.gsfc.nasa.gov/POLARRIS/). Still, efficient and accurate PRD operators, like the one in Mahale et al. (2019) for rain, are still lacking and in need for ice- and mixed-phase species to make PRD assimilation more feasible and efficient.

The current status of using PRD is due to the PRD and products thereof having been generated from radar engineering and meteorological points of view, with little influence from the NWP community thus far. Rigorous retrieval methods developed from the information theory and NWP communities have not been successfully adapted. Radar meteorology and NWP fields developed and evolved from their communities independently from each other. Radar meteorology was developed based on the theory/model of electromagnetic wave scattering by hydrometeors, and by observing and relating radar measurements for understanding and estimat- ing weather with empirical relations. NWP, on the other hand, is formulated from a set of physical, dynamic and thermodynamic conservation equations. There has not been enough connection between the two research areas. This disconnect is reflected in the different variables commonly used to represent the weather state [e.g., the water mixing ratio $(q)$ in NWP models, but the rain rate $(R)$ in radar meteorology], the difference of unit usage between NWP state and radar variables, and the different values used to characterize PRD errors for two different realities in the two communities. For example, it is generally accepted by the radar meteorology community that the measurement error for $Z$ is about $1.0 \mathrm{~dB}$, which is usually ignored in direct observation retrieval; however, a 2.0-5.0 dB error is usually used in the NWP community. The gaps between radar meteorology and NWP need to be bridged, and the approaches adapted to use PRD need to be aligned for optimal results.

\section{A unified statistical approach}

Since the purpose of both radar meteorology and NWP is to understand and predict weather, one way to advance the usage of PRD is to improve model parameterizations and initialization for more accurate weather forecasts and warnings. Considering that radar measurements contain errors, weather states vary, observational information is not enough and not uniformly available across the atmosphere, and physical constraints and prior information are needed to facilitate retrieval, a statistical approach is warranted. In this framework, both state variables and radar measurements are treated as random variables, and both the prior background and observations are used.

As shown in Fig. 4, let $\boldsymbol{x}$ be the state vector and $\boldsymbol{y}$ the polarimetric radar variable vector; and they are related by the
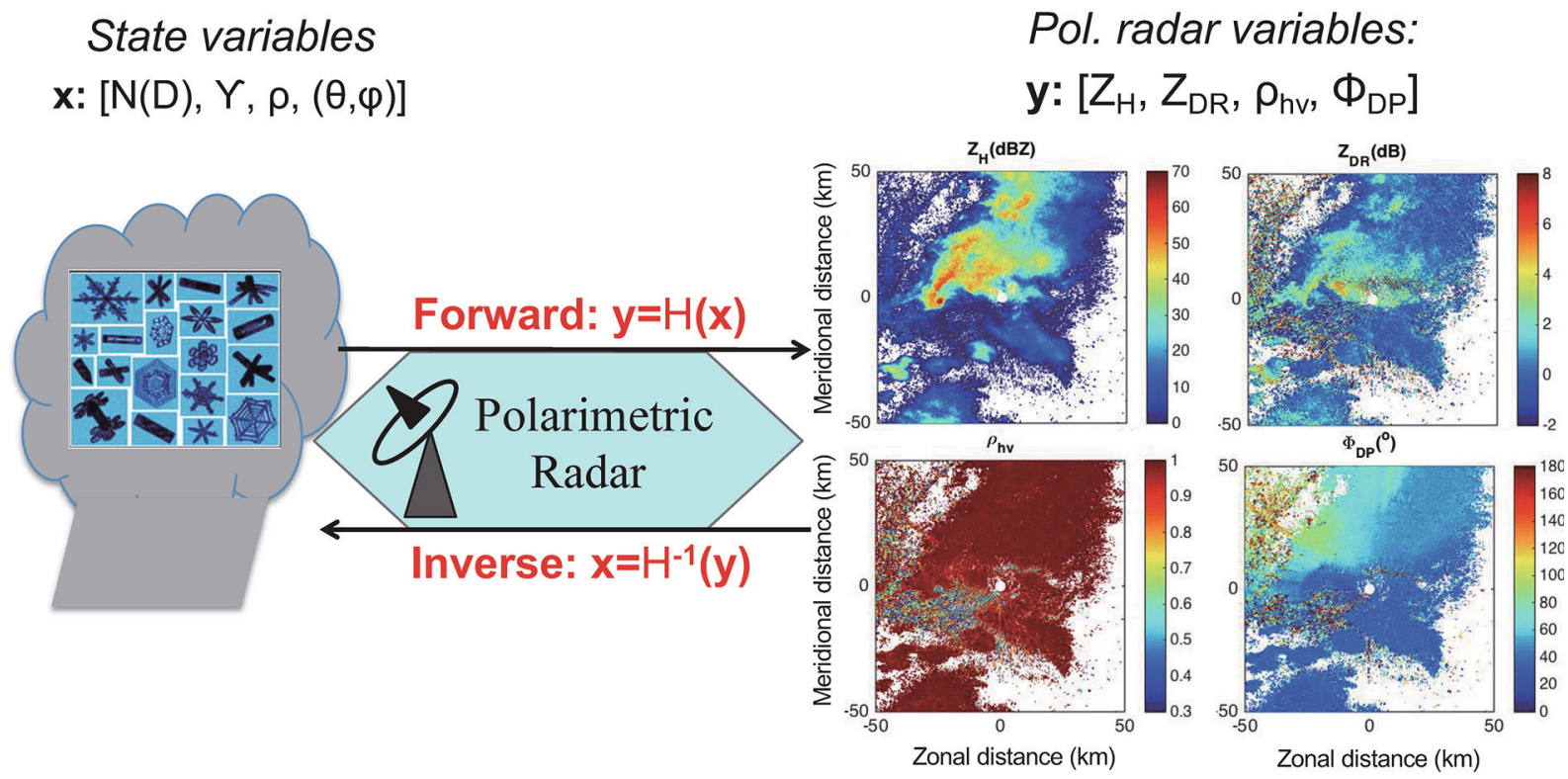

Fig. 4. Sketch of the weather physics state variables of DSD $[N(D)]$, axis ratio $(\gamma)$, density $(\rho)$, and orientation angles $(\theta, \varphi)$ versus polarimetric radar measurables. 
forward operator as: $\boldsymbol{y}=H(\boldsymbol{x})$. An optimal retrieval involves finding the state vector $\boldsymbol{x}$ that has the best match with a given prior background, $\boldsymbol{x}_{\mathrm{b}}$, and a set of observations, $\boldsymbol{y}_{\mathrm{o}}$, while accounting for their given uncertainties. This is equivalent to minimizing the cost function $J$,

$$
J=\left(\boldsymbol{x}-\boldsymbol{x}_{\mathrm{b}}\right)^{\mathrm{T}} \boldsymbol{B}^{-1}\left(\boldsymbol{x}-\boldsymbol{x}_{\mathrm{b}}\right)+\left[\boldsymbol{y}_{\mathrm{o}}-H(\boldsymbol{x})\right]^{\mathrm{T}} \boldsymbol{O}^{-1}\left[\boldsymbol{y}_{\mathrm{o}}-H(\boldsymbol{x})\right],
$$

where $\boldsymbol{B}$ and $\boldsymbol{O}$ represent the background error covariance and observation error covariance, respectively, and $H(\ldots)$ is a forward observation operator. This serves as the basis for variational (VAR) analysis and ensemble Kalman filter (EnKF) analysis (Lorenc, 1986). The VAR approach has been used in improving QPE and microphysics retrieval with PRD in Hogan (2007), Cao et al. (2010, 2013), Yoshikawa et al. (2014), and Chang et al. (2016), in which the background information is obtained from previous measurements/knowledge. In EnKF analysis, the forward operator is assumed to be linear, the flow-dependent covariance $\boldsymbol{B}$ is estimated from a limited number of ensemble forecasts, and the analyzed state vector is solved from Eq. (6) iteratively, whose application in data assimilation (DA) with PRD is presented in section 5 .

The procedure to derive $Z-R$ relations is a special case of the VAR approach, in which background information is lacking [the first term in Eq. (6) is ignored], only the $Z$ observations are used, and each data point is normally equally weighted to fit with a power-law relation $\left(Z=a R^{b}\right)$ in the logarithm domain to determine the coefficients $a$ and $b$. Hence, the $Z-R$ relation highly depends on data collection/selection, filtering, and the weighting and fitting procedure used, which is obviously not optimal because the data quality and weighting issues cannot be taken into account in rain estimation once a $Z-R$ relation is chosen. Therefore, the statistical ap- proach represented by Eq. (6) is more fundamental and complete in formulating PRD-based retrieval, and has the potential to achieve optimal usage because the prior background information can be used and measurement error effects are included. Since it is already in use in the NWP community for radar data assimilation, the statistical approach is one way to align the radar meteorology/hydrology and NWP communities, and is applicable to both observation-based and DAbased retrievals.

While the statistical retrieval approach has been formulated and successfully used in the data assimilation community (Rodgers, 2000; Kalnay, 2003), it has seen little success in the optimal usage of PRD due to its complexity. The reason for this is that there are many issues in optimally utilizing PRD for improving QPE and QPF, as discussed in the previous section (section 3). Importantly, there are large uncertainties in storm-scale NWP models and model microphysics parameterization (further discussed in section 5). These large errors in NWP that DA depends on as background information [first term of Eq. (6)], and large uncertainty and nonlinearity in PRD operators prevent the substantial positive impact of limited information from PRD [2nd term of Eq. (6)].

Considering all aforementioned issues, the vision for optimal utilization of PRD with different components is modified from Zhang (2016, Fig. 7.14) and shown in Fig. 5. As sketched in the top row (red) of the figure, observation-based studies and retrievals are normally conducted in radar meteorology, which deals with in-situ measurements and processing, PRD observation, $\mathrm{HC}$ and precipitation estimation through empirical relations, and PRD quality control (QC) and error characterization to determine $\boldsymbol{O}$. The direct and empirical methods have been used in observation-based studies, but the error covariance and prior information are usually ig-

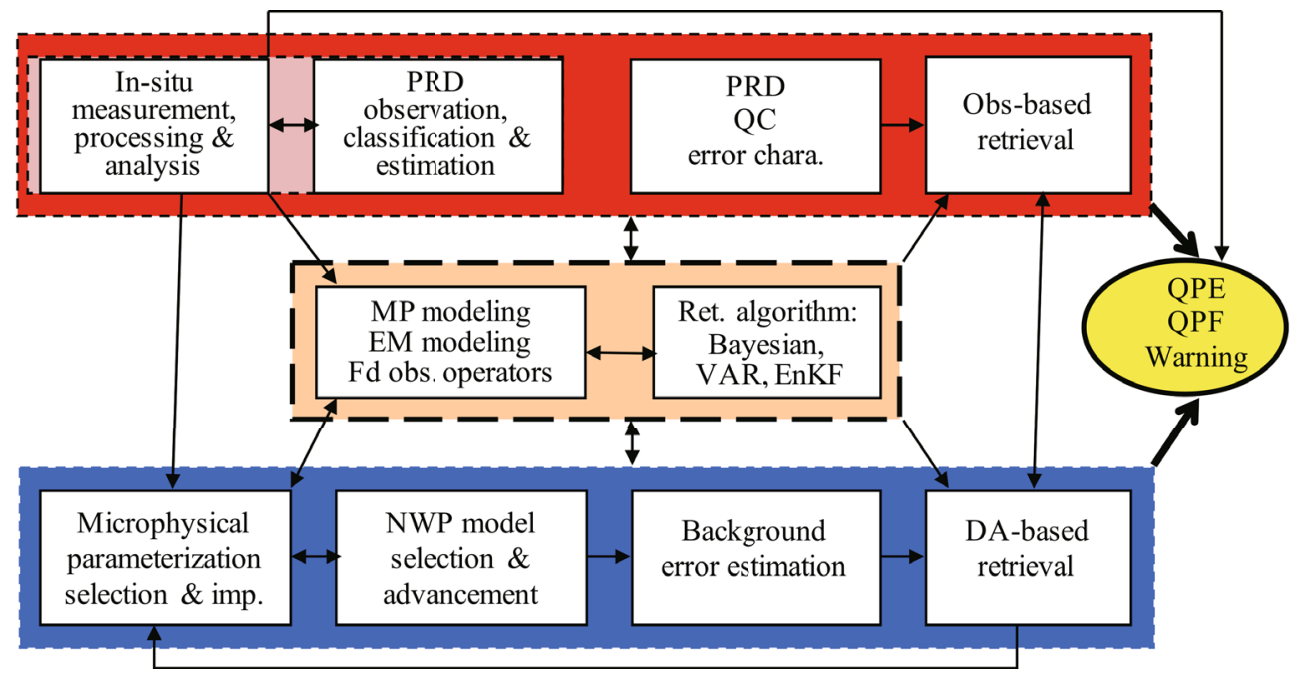

Fig. 5. Sketch of the different components for optimal utilization of PRD and connections between observation-based retrieval (red) that can be used in radar meteorology and DA-based retrieval (blue) used in NWP. Acronyms/abbreviations are: polarimetric radar data (PRD); quality control (QC); microphysics (MP); electromagnetic (EM); forward observation operators (Fd obs. operators); variational (VAR); Ensemble Kalman filter (EnKF); quantitative precipitation estimation (QPE); quantitative precipitation forecasting (QPF), numerical weather prediction (NWP); data assimilation (DA). 
nored in the retrieval. As shown in the bottom row (blue) of Fig. 5, DA-based retrieval/analysis is used by the NWP community. It involves selection and improvement of microphysical parameterization schemes and NWP models, as well as estimation of $\boldsymbol{B}$. The stochastic nature of microphysical variables contributes significantly, which is ignored in most current model parameterizations, and should be included in future improvements (Finlon et al., 2016). As sketched in the middle row (brown), the forward operators, which result from microphysics modeling and electromagnetic modeling, and statistical retrieval algorithms, are required for both observation-based and DA-based retrievals. Each of the retrievals needs to have compatible microphysics models, such as DSD/PSD models, and shape/density relations, electromagnetic modeling and calculations, etc., as well as statistical retrieval algorithms that can handle measurement error and background information and covariance, such as the one presented earlier in this section. To achieve best possible results, all the components need to be accurately determined and selected, and used in conjunction and cross-verified with each other in the statistical retrieval algorithms as depicted in the figure.

The statistical retrieval allows observation errors and prior information to be characterized and included, and it reduces to the direct retrieval when the observation errors are zero and the prior information is absent. The optimal usage of PRD is to find the balance between the measurements used and the prior information obtained for a specific application as well as errors in the measurements and information used and characterized. Since observation errors are included, the contribution from each measurement is automatically weighted differently based on its relative information compared with the error to produce optimal estimates, as done in Mahale et al. (2019) for rain microphysics retrieval, without having to empirically change one estimator to another, as in Eqs. (1)-(5). To include flow-dependent background information in the retrieval, assimilating PRD into an NWP model is needed, which is discussed next.

\section{An example of DA analysis with PRD}

It is accepted that one of the main uses of radar observations, including $\mathrm{PRD}$, is the assimilation of these observations into a convective-scale NWP model. It was realized that the assimilation of reflectivity data helps reduce the spinup problem (Sun and Crook, 1997, 1998; Hu et al., 2006; Gao and Stensrud, 2012), and a variety of real case studies have shown these data help improve QPF (Jung et al., 2012; Ge et al., 2013; Yussouf et al., 2013, 2015; Putnam et al., 2014, 2017a; Wheatley et al., 2014; Snook et al., 2016). However, many issues still exist because although reflectivity has proven to be useful, reflectivity alone is insufficient to analyze all the state variables included in advanced multimoment microphysics schemes (e.g., hydrometeor mixing ratios and number concentrations). PRD may help resolve these issues with additional information about cloud microphysics and physics processes (Vivekanandan et al., 1999; Zhang et al., 2006; Ryzhkov et al., 2013a, b; Kumjian et al., 2014, Carlin et al., 2016).

Several studies have been conducted to initialize an NWP model with PRD (Wu et al., 2000; Jung et al., 2008b; Li and Mecikalski, 2010; Posselt et al., 2015, Li et al., 2017). However, in those studies, polarimetric data were assimilated indirectly (e.g. Wu et al., 2000; Li and Mecikalski, 2010), assimilated directly but in the observing system simulation experiment framework (Jung et al., 2008b), or using a singlemoment microphysics scheme, which is unable to simulate size sorting (e.g., Posselt et al., 2015; Li et al., 2017). Recently, there was a more advanced PRD assimilation of $Z_{\mathrm{DR}}$ in addition to $Z$ and $v_{\mathrm{r}}$ using an EnKF and a multi-moment microphysics scheme for the 20 May 2013 Newcastle-Moore tornadic supercell case, as shown in Fig. 6. The analysis with differential reflectivity increased the low-level $Z_{\mathrm{DR}}$ values with fewer, larger raindrops along the right forward flank of the supercell adjacent to the updraft in the vicinity of the observed $Z_{\mathrm{DR}}$ arc polarimetric signatures (Kumjian and Ryzhkov, 2008). The $Z_{\mathrm{DR}}$ values are lower downshear in the forward flank in the storm in the transition region between and the supercell immediately to its north. Additionally, the gradient of hail mean mass diameter was larger aloft and similar to hail patterns studied in Dawson et al. (2014, see their Fig. 17), which demonstrated the importance of size sorting of rimed-ice in producing a low-level $Z_{\mathrm{DR}}$ arc, further indicating the positive impact of PRD assimilation.

There is some evidence that PRD also contains information about storm dynamic and moisture information, which can also be used to initialize NWP models (Snyder et al., 2015; Carlin et al., 2017). Such studies indicate that $Z_{\mathrm{DR}}$ columns can be used to identify regions of positive temperature perturbations from latent heat release due to condensation and/or freezing. Realizing this, Carlin et al. (2017) explored the impact of assimilating real PRD through a modified cloud analysis (Hu et al., 2006). Preliminary findings suggested a marked improvement in analyzed updraft location. Quantitative analysis of Equitable Threat Score for $Z$ also revealed improved performance when using the modified cloud analysis routine in several experiments with the $Z_{\mathrm{DR}}$ column than that of the control experiment without using the $Z_{\mathrm{DR}}$ column. The study is also very preliminary.

Many challenges still remain for PRD assimilation. The 20 May study demonstrated how the number of predicted moments in model microphysics schemes affect microphysical processes, where excessive size sorting known to occur with double moment microphysics schemes (Dawson et al., 2010; Morrison and Milbrandt, 2011; Dawson et al., 2015) had a significant impact on the effectiveness of PRD data assimilation. Also, the forward operators and microphysics schemes must be improved, specifically in regard to the treatment of frozen hydrometeors as well as mixed-phase hydrometeors, which most microphysics schemes do not predict. Additionally, the choice of model resolution has a significant impact on the detailed polarimetric patterns and signatures that can be resolved. The 20 May study used a 500-m grid spacing, 


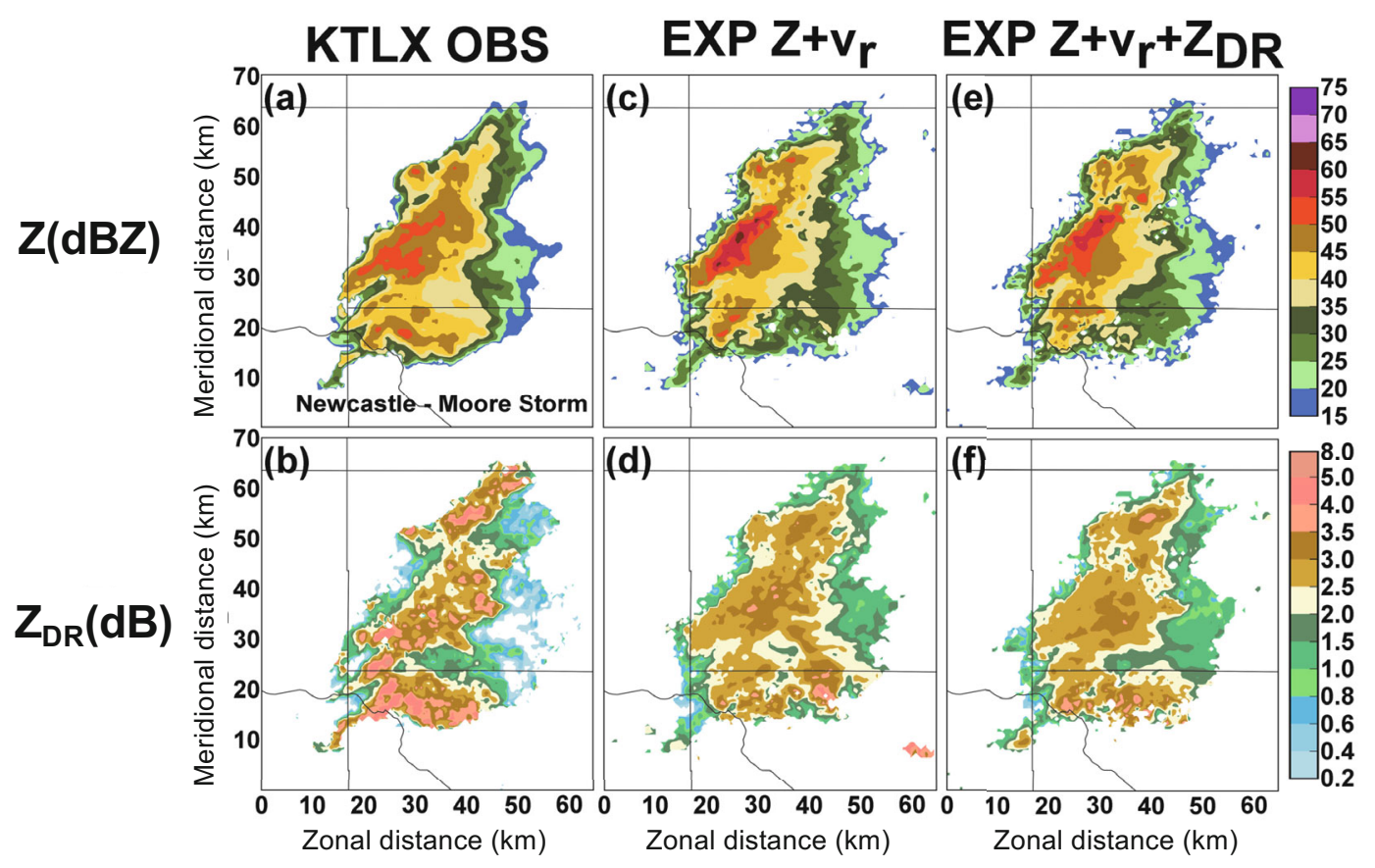

Fig. 6. Comparison between polarimetric radar observation and DA analysis: (a) observed reflectivity and (b) differential reflectivity from KTLX of the Newcastle-Moore tornadic supercell at 1938 UTC 20 May 2013, with storm location noted in (a); (c) analyzed reflectivity and (d) differential reflectivity at 1940 UTC from an EnKF experiment that assimilated only reflectivity and radial velocity (EXP $Z+v_{\mathrm{r}}$ ), as well as (e) analyzed reflectivity and (f) differential reflectivity from an EnKF experiment that assimilated differential reflectivity in addition to reflectivity and radial velocity $\left(\mathrm{EXP} Z+v_{\mathrm{r}}+Z_{\mathrm{DR}}\right.$ ). [Adapted from Putnam et al. (2019); (C) American Meteorological Society; used with permission].

and continuing advances in computer power can allow for even higher resolution experiments. PRD assimilation is still in its infancy, but the additional microphysical information provided can help to improve our understanding of current model deficiencies, both through assimilation experiments like those referenced here and direct simulation comparisons similar to Johnson et al. (2016) and Putnam et al. (2017b).

\section{Polarimetric PAR technology}

While radar polarimetry allows for more microphysical information measured, there is increasing need for faster data updates. To timely detect and predict fast evolving weather phenomena such as tornadoes and downbursts, it is desirable to rapidly acquire volumetric radar data at intervals of one minute or less, as opposed to the current five minutes with WSR-88D. For this reason, rapid scan PAR with agile beam scanning capability was recently introduced to the weather community (Weber et al., 2007; Zrnic et al., 2007; Heinselman and Torres, 2011). Simulation experiments demonstrate assimilation of PAR observations at 1-min intervals over a short 15-min period yields significantly better analyses and ensemble forecasts than those produced using WSR-88D observations (Yussouf and Stensrud, 2010). Thus, there is the potential to increase the tornado warning lead time beyond the present 10 to 15 minutes.
Another motivation behind introducing PAR technology is the MPAR (multifunction PAR) and SENSR (Spectrum Efficient National Surveillance Radar) initiatives to use one radar network to replace the four radar networks in the United States of the (1) National Weather Surveillance Radar (WSR88D), (2) Terminal Doppler Weather Radar (TDWR) for detecting low altitude wind shear; (3) Airport Surveillance Radar (ASR) for air traffic control; and (4) Air Route Surveillance Radar (ARSR) for long-range air surveillance (Stailey and Hondl, 2016). Since all the radars share the same principle in detecting electromagnetic wave scattering from targeted media, it is efficient to use a single radar network to service all the missions. To do so, PAR fast scanning capability is needed. Because WSR-88D has dual-polarization capability, future PAR for weather observation needs to have polarimetry capability as well, i.e., polarimetric PAR (PPAR).

PPARs have been developed for satellite and military applications, but with limited scanning angles (Jordan et al., 1995). For ground-based weather measurements, it is challenging to develop the PPAR technology because of the requirements of wide angle scan and high accuracy for polarimetric measurements $\left(Z_{\mathrm{DR}}\right.$ error $<0.2 \mathrm{~dB}, \rho_{\mathrm{hv}}$ error $<0.01$, $\varphi_{\text {DP }}$ error $\left.<3^{\circ}\right)$. Nevertheless, the challenges and difficulties have not curbed the enthusiasm and efforts of the community to formulate PPAR theory and design and develop PPAR systems for future weather observation and multi-missions (Zhang et al., 2009). 
Several PPAR configurations and systems have been attempted, including: (1) a planar PPAR (PPPAR) with onedimensional (1D) electronic scan capability antenna mounted on a mechanically steerable platform, e.g., the Collaborative Adaptive Sensing of the Atmosphere phase tilted radar (Hopf et al., 2009); (2) a two-dimensional (2D) electronic scan PPPAR, like the National Severe Storms Laboratory (NSSL) ten-panel demonstrator (shown in Fig. 7a); and (3) a cylindrical PPAR (CPPAR) demonstrator (Fig. 7b) being developed jointly by the University of Oklahoma (OU) and the NSSL (Zhang et al., 2011, Karimkashi and Zhang, 2015, Fulton et al., 2017). Each of these PPARs can cover the volume more quickly than a mechanically steered beam due to beam agility, versatility in beam shape, speed of changing pointing direction, and/or four radars operating simultaneously.

(a) NSSL TPD

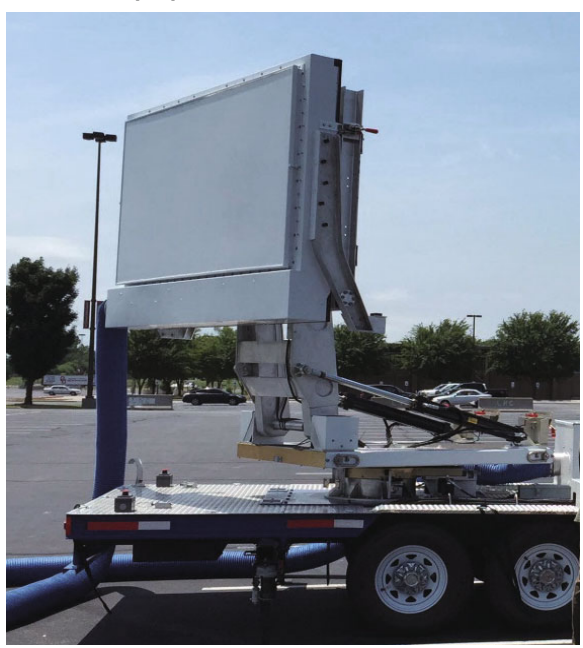

(b) OU-NSSL CPPAR

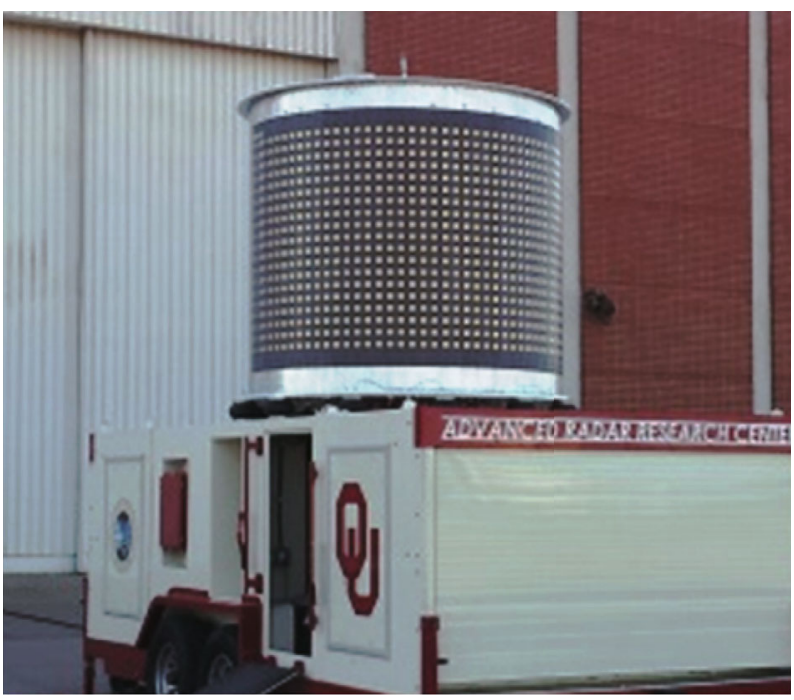

Fig. 7. Pictures of polarimetric PARs that are under development: (a) NSSL 2D ten-panel planar PPAR (PPPAR) demonstrator (TPD); and (b) OU-NSSL cylindrical PPAR (CPPAR).
Although a considerable amount of effort has been put into developing PPPAR, no satisfactory polarimetric weather measurements have appeared in the literature. Initial testing results of CPPAR are promising, but still preliminary, as documented in a technical report by Byrd et al. (2017). A set of CPPAR measurements compared to the WSR-88D KTLX measurements are duplicated in Fig. 8. Since the CPPAR has a lower power $(<2 \mathrm{~kW})$ and smaller aperture $(<2 \mathrm{~m}$ in diameter), the lower sensitivity is expected, yielding less data coverage than KTLX. It is promising to see the similar features in $Z_{\mathrm{DR}}$, and $Z_{\mathrm{H}}$ appear in both with the CPPAR and the KTLX measurements. However, $\rho_{\mathrm{hv}}$ is low and not up to expectations due to the antenna beam mismatch and other system instability issues. The beam mismatch is being addressed by a redesign of the frequency-scan dual-polarization column antennas (Saeidi-Manesh et al., 2017). The CPPAR electronics is also being redesigned and rebuilt to have a stable system so that many CPPAR related issues such as commutating scan, sector-to-sector isolation, surface wave effects, and accurate weather measurements can be addressed/demonstrated.

Achieving comparable or better accuracy in the polarimetric measurements than on the WSR-88D is challenging. It is most difficult for the 2D PPPAR with multiple faces because the polarization basis for a planar array changes and becomes coupled for a pair of radiators and can cause bias/error that is much larger than the maximum allowed error. The 1D PPPAR with a mechanical scan in azimuth is feasible because of its relative simplicity in maintaining polarization purity and azimuthal scan invariant beam characteristics, but needs to be demonstrated. CPPAR is an alternative solution for accurate polarimetric PAR measurements, which scans in the azimuth by commutating its beam position to achieve the high performance beam characteristics like the 1D PPPAR. Further research and development are needed to realize this potential.

\section{Conclusions and discussion}

This paper reviews the status of weather radar polarimetry, identifies the limitations and challenges of using PRD, and proposes possible solutions and unification of approaches. Also discussed and explored are the challenges, research and development for future weather observation using PAR polarimetry technology. The main objective of this paper is to raise these issues and generate consensus for finding a path forward.

Collaborative efforts between the radar engineering/ meteorology/hydrology and NWP communities are necessary to develop feasible new technology and to more efficiently utilize the existing PRD to better monitor, quantify, and forecast weather. Although radar data are becoming a dominant factor and PRD are useful in short-term forecasting and warning, PRD alone do not guarantee accurate shortterm forecasts. Other measurements such as satellite remote sensing data and cellular communication signals (Overeem et al., 2013) can be included to enhance the information con- 
(a) $\quad \operatorname{CPPAR}_{\mathbf{H}}$ (dBZ)

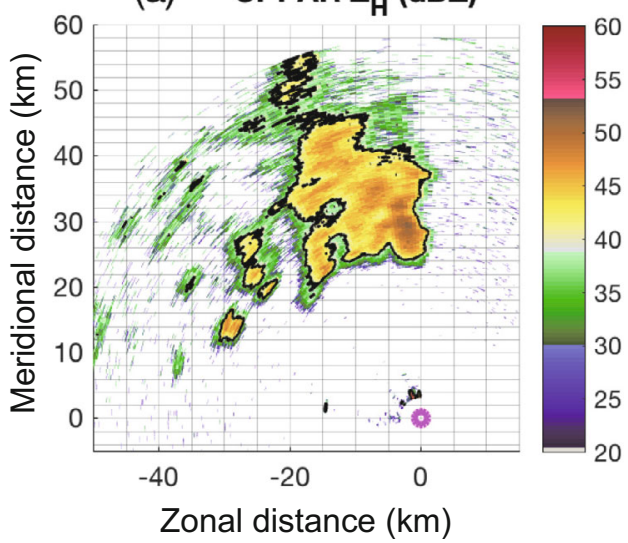

(c) $\quad$ CPPAR $Z_{D R}$ (dB)

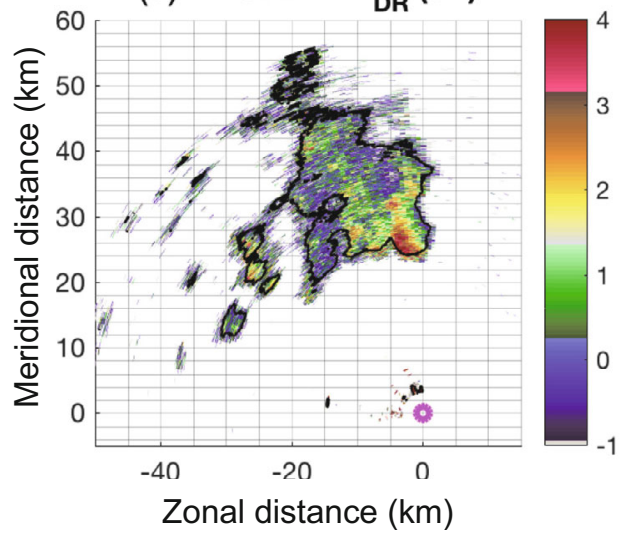

(e) CPPAR $\rho_{\text {hv }}$

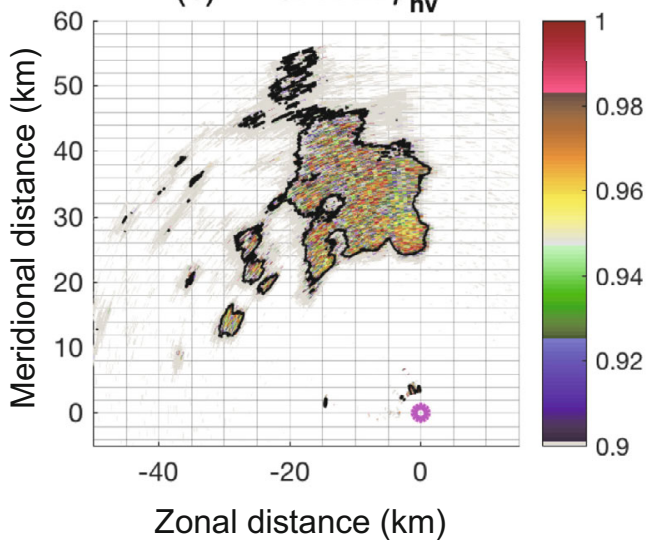

(b) $\quad \mathrm{KTLXZ}_{\mathrm{H}}(\mathrm{dBZ})$

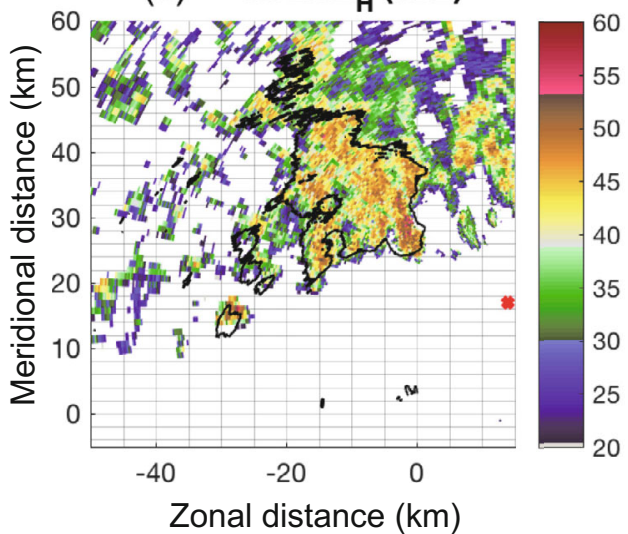

(d) $\quad K T L X Z_{D R}(d B)$
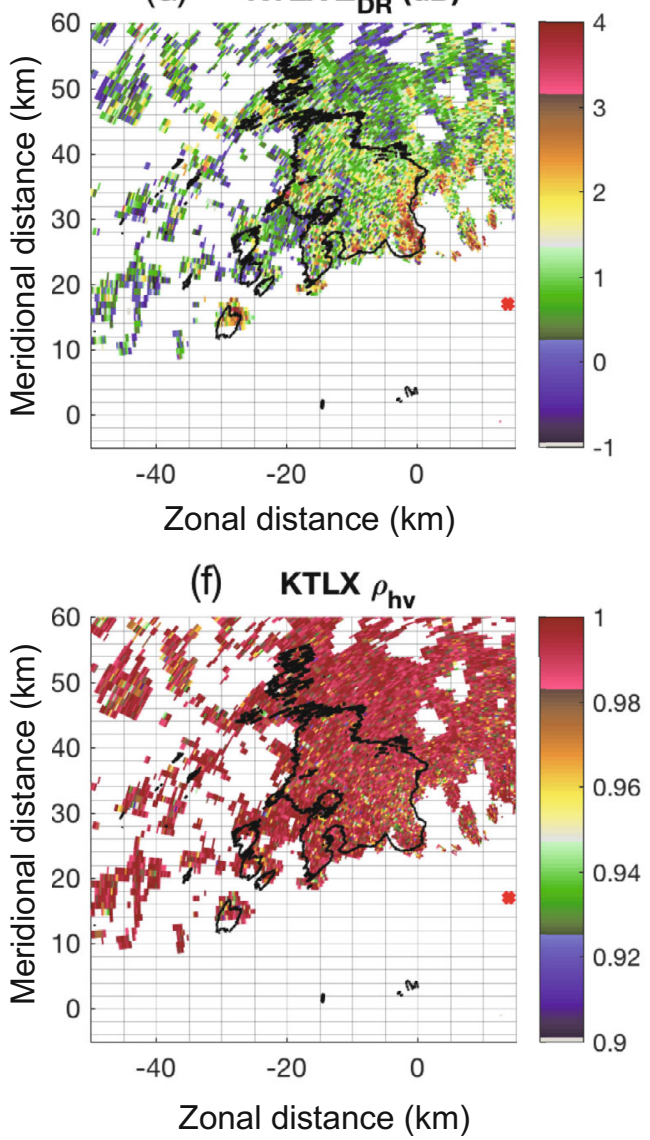

Fig. 8. Comparison of polarimetric weather measurements between the CPPAR demonstrator located at the pink circle and the WSR-88D KTLX radar at the red asterisk. The data were collected at 0413:47 UTC 10 September 2016 for CPPAR and 0413:50 UTC 10 September 2016 for KTLX. Data points with $Z<20 \mathrm{dBZ}$ were excluded. There are echoes in the KTLX data, but not in the CPPAR data, because CPPAR has a much lower sensitivity due to its smaller antenna and lower transmitted power.

tent. On the other hand, NWP model microphysics parameterizations need to be improved so that the utilization of PRD can make substantial contributions to improving the accuracy of weather forecasts. Direct comparisons between NWPsimulated PRD and polarimetric radar measurements open a feasible way to reveal model deficiencies and to improve model physics and microphysics parameterizations. Assimilation of PRD and data from other in-situ and remote sensors, such as satellites, into high-resolution convective-scale NWP models, together with judicious interpretation by meteorologists, is required to produce further improvements of QPE, QPF, and severe weather warning lead time.

Acknowledgements. The research was supported by the NOAA (Grant Nos. NA16AOR4320115 and NA11OAR4320072) and NSF (Grant No. AGS-1341878). The authors would like to 
thank the engineers at the NSSL and OU/ARRC for their support of the CPPAR development.

Open Access This article is distributed under the terms of the Creative Commons Attribution License which permits any use, distribution, and reproduction in any medium, provided the original author(s) and the source are credited.

\section{REFERENCES}

Andrić, J., M. R. Kumjian, D. S. Zrnić, J. M. Straka, and V. M. Melnikov, 2013: Polarimetric Signatures above the Melting Layer in Winter Storms: An Observational and Modeling Study. Journal of Applied Meteorology and Climatology, 52, 682-700.

Bluestein, H. B., and Coauthors, 2014: Radar in atmospheric sciences and related research: Current systems, emerging technology, and future needs. Bull. Amer. Meteor. Soc., 95, 18501861, https://doi.org/10.1175/BAMS-D-13-00079.1.

Brandes, E. A., and K. Ikeda, 2004: Freezing-level estimation with polarimetric radar. J. Appl. Meteor., 43, 1541-1553, https:// doi.org/10.1175/JAM2155.1.

Brandes, E. A., G. F. Zhang, and J. Vivekanandan, 2002: Experiments in rainfall estimation with a polarimetric radar in a subtropical environment. J. Appl. Meteor., 41, 674-685, https:// doi.org/10.1175/1520-0450 (2002) 041<0674:EIREWA > 2.0. $\mathrm{CO} ; 2$.

Bringi, V. N., and V. Chandrasekar, 2001: Polarimetric Doppler Weather Radar: Principles and Applications. Cambridge University Press, $636 \mathrm{pp}$.

Brown, B. R., M. M. Bell, and A. J. Frambach, 2016: Validation of simulated hurricane drop size distributions using polarimetric radar. Geophys. Res. Lett., 43(2), 910-917, https://doi.org/ 10.1002/2015GL067278.

Bukovčić, P., D. Zrnić, and G. F. Zhang, 2017: Winter precipitation liquid-ice phase transitions revealed with polarimetric radar and 2DVD observations in central Oklahoma. Journal of Applied Meteorology and Climatology, 56(5), 1345-1363, https://doi.org/10.1175/JAMC-D-16-0239.1.

Byrd, A., C. Fulton, R. Palmer, S. Islam, D. Zrnic, R. Doviak, R. Zhang, and G. Zhang, 2017: First weather observations with a cylindrical polarimetric phased array radar. Internal Technical Report.

Cao, Q., G. F. Zhang, E. A. Brandes, and T. J. Schuur, 2010: Polarimetric radar rain estimation through retrieval of drop size distribution using a Bayesian approach. Journal of Applied Meteorology and Climatology, 49, 973-990, https://doi.org/ 10.1175/2009JAMC2227.1

Cao, Q., G. F. Zhang, and M. Xue, 2013: A variational approach for retrieving raindrop size distribution from polarimetric radar measurements in the presence of attenuation. Journal of Applied Meteorology and Climatology, 52, 169185, https://doi.org/10.1175/JAMC-D-12-0101.1.

Carlin, J. T., A. V. Ryzhkov, J. C. Snyder, and A. Khain, 2016: Hydrometeor mixing ratio retrievals for storm-scale radar data assimilation: Utility of current relations and potential benefits of polarimetry. Mon. Wea. Rev., 144, 2981-3001, https:// doi.org/10.1175/MWR-D-15-0423.1.

Carlin, J. T., J. D. Gao, J. C. Snyder, and A. V. Ryzhkov, 2017: Assimilation of $Z_{\mathrm{DR}}$ columns for improving the spinup and forecast of convective storms in storm-scale models: Proof- of-concept experiments. Mon. Wea. Rev., 145, 5033-5057, https://doi.org/10.1175/MWR-D-17-0103.1.

Chandrasekar V., R. Keränen, S. Lim, and D. Moisseev, 2013: Recent advances in classification of observations from dual polarization weather radars. Atmospheric Research, 119, 97 111, https://doi.org/10.1016/j.atmosres.2011.08.014.

Chang, W.-Y., T.-C. C. Wang, and P.-L. Lin, 2009: Characteristics of the raindrop size distribution and drop shape relation in typhoon systems in the western Pacific from the 2D video disdrometer and NCU C-band polarimetric radar. J. Atmos. Oceanic Technol., 26(10), 1973-1993, https://doi.org/ 10.1175/2009JTECHA1236.1.

Chang, W.-Y., J. Vivekanandan, K. Ikeda, and P.-L. Lin 2016: Quantitative precipitation estimation of the epic 2013 Colorado flood event: Polarization radar-based variational scheme. Journal of Applied Meteorology and Climatology, 55(7), 1477-1495, https://doi.org/10.1175/JAMC-D-150222.1 .

Chen, G., and Coauthors, 2017: Improving polarimetric C-band radar rainfall estimation with two-dimensional video disdrometer observations in Eastern China. Journal of Hydrometeorology, 18(5), 1375-1391, https://doi.org/10.1175/JHMD-16-0215.1.

Chen, H. N., and V. Chandrasekar, 2015: The quantitative precipitation estimation system for dallas- fort worth (DFW) urban remote sensing network. J. Hydrol., 531, 259-271, https:// doi.org/10.1016/j.jhydrol.2015.05.040.

Dawson, D. T., M. Xue, J. A. Milbrandt, and M. K. Yau, 2010: Comparison of evaporation and cold pool development between single-moment and multimoment bulk microphysics schemes in idealized simulations of tornadic thunderstorms. Mon. Wea. Rev., 138, 1152-1171, https://doi.org/10.1175/ 2009MWR2956.1.

Dawson, D. T., M. Xue, J. A. Milbrandt, and A. Shapiro, 2015 Sensitivity of real-data simulations of the 3 May 1999 Oklahoma City tornadic supercell and associated tornadoes to multimoment microphysics. Part I: Storm- and tornado-scale numerical forecasts. Mon. Wea. Rev., 143, 2241-2265, https:// doi.org/10.1175/MWR-D-14-00279.1.

Dawson, D. T., E. R. Mansell, Y. Jung, L. J. Wicker, M. R. Kumjian, and M. Xue, 2014: Low-level $Z_{\mathrm{DR}}$ signatures in supercell forward flanks: The role of size sorting and melting of hail. J. Atmos. Sci., 71, 276-299, https://doi.org/10.1175/JASD-13-0118.1.

Didlake, A. C., and M. R. Kumjian, 2017: Examining polarimetric radar observations of bulk microphysical structures and their relation to vortex kinematics in Hurricane Arthur (2014). Mon. Wea. Rev., 145(11), 4521-4541, https://doi.org/ 10.1175/MWR-D-17-0035.1.

Dolan, B., S. A. Rutledge, S. Lim, V. Chandrasekar, and M. Thurai, 2013: A robust C-band hydrometeor identification algorithm and application to a long-term polarimetric radar dataset. Journal of Applied Meteorology and Climatology, 52, 2162 2186, https://doi.org/10.1175/JAMC-D-12-0275.1.

Doviak, R. J., and D. S. Zrnić, 1993: Doppler Radar and Weather Observations. 2nd ed. Academic Press, 562 pp.

Doviak, R. J., V. Bringi, A. Ryzhkov, A. Zahrai, and D. S. Zrnić, 2000: Considerations for polarimetric upgrades to operational WSR-88D radars. J. Atmos. Oceanic Technol., 17, 257-278, https://doi.org/10.1175/1520-0426(2000)017<0257:CFPUTO> 2.0.CO;2.

Eccles, P. J., and D. Atlas, 1973: A dual-wavelength radar hail 
detector. J. Appl. Meteor., 12(5), 847-854, https://doi.org/ 10.1175/1520-0450(1973)012<0847:ADWRHD>2.0.CO;2.

Figueras i Ventura, J., and P. Tabary, 2013: The new French operational polarimetric radar rainfall rate product. Journal of Applied Meteorology and Climatology, 52(8), 1817-1835, https://doi.org/10.1175/JAMC-D-12-0179.1.

Finlon, J. A., G. M. McFarquhar, R. M. Rauber, D. M. Plummer, B. F. Jewett, D. Leon, and K. R. Knupp, 2016: A comparison of X-band polarization parameters with in situ microphysical measurements in the comma head of two winter cyclones. Journal of Applied Meteorology and Climatology, 55, 25492574, https://doi.org/10.1175/JAMC-D-16-0059.1.

Fulton, C., and Coauthors, 2017: Cylindrical polarimetric phased array radar: Beamforming and calibration for weather applications. IEEE Trans. Geosci. Remote Sens., 55(5), 28272841, https://doi.org/10.1109/TGRS.2017.2655023.

Gao, J. D., and D. J. Stensrud, 2012: Assimilation of reflectivity data in a convective-scale, cycled 3DVAR framework with hydrometeor classification. J. Atmos. Sci., 69(3), 1054-1065, https://doi.org/10.1175/JAS-D-11-0162.1.

Ge, G. Q., J. D. Gao, and M. Xue, 2013: Impacts of assimilating measurements of different state variables with a simulated supercell storm and three-dimensional variational method. Mon. Wea. Rev., 141(8), 2759-2777, https://doi.org/10.1175/ MWR-D-12-00193.1.

Giangrande, S. E., and A. V. Ryzhkov, 2008. Estimation of rainfall based on the results of polarimetric echo classification. Journal of Applied Meteorology and Climatology, 47, 2445-2462, https://doi.org/10.1175/2008JAMC1753.1.

Giangrande, S. E., J. M. Krause, and A. V. Ryzhkov, 2008: Automatic designation of the melting layer with a polarimetric prototype of the WSR-88D radar. Journal of Applied Meteorology and Climatology, 47, 1354-1364, https://doi.org/ 10.1175/2007JAMC1634.1.

Giangrande, S. E., R. McGraw, and L. Lei, 2013: An application of linear programming to polarimetric radar differential phase processing. J. Atmos. Oceanic Technol., 30, 17161729, https://doi.org/10.1175/JTECH-D-12-00147.1.

Gosset, M., and H. Sauvageot, 1992: A dual-wavelength radar method for ice-water characterization in mixed-phase clouds. J. Atmos. Oceanic Technol., 9, 538-547, https://doi.org/ 10.1175/1520-0426(1992)009<0538:ADWRMF>2.0.CO;2.

Griffin, E. M., T. J. Schuur, and A. V. Ryzhkov, 2018: A polarimetric analysis of ice microphysical processes in snow, using quasi-vertical profiles. Journal of Applied Meteorology and Climatology, 57, 31-50, https://doi.org/10.1175/JAMCD-17-0033.1.

Heinselman, P. L., and S. M. Torres, 2011: High-temporalresolution capabilities of the national weather radar testbed phased-array radar. Journal of Applied Meteorology and Climatology, 50, 579-593, https://doi.org/10.1175/2010JAMC 2588.1.

Hogan, R. J., 2007: A variational scheme for retrieving rainfall rate and hail reflectivity fraction from polarization radar. Journal of Applied Meteorology and Climatology, 46, 1544-1564, https://doi.org/10.1175/JAM2550.1.

Hopf, A. P., J. L. Salazar, R. Medina, V. Venkatesh, E. J. Knapp, S. J. Frasier, and D. J. McLaughlin, 2009: CASA phased array radar system description, simulation and products. Proc. 2009 IEEE Int. Geoscience and Remote Sensing Symposium, Cape Town, South Africa, IEEE, https://doi.org/10.1109/IGARSS. 2009.5418262.
Hu, M., M. Xue, and K. Brewster, 2006: 3DVAR and cloud analysis with WSR-88D level-II data for the prediction of the Fort Worth, Texas, Tornadic thunderstorms. Part I: Cloud analysis and its impact. Mon. Wea. Rev., 134(2), 675-698, https:// doi.org/10.1175/MWR3092.1.

Huang, H., G. F. Zhang, K. Zhao, and S. E. Giangrande, 2017: A hybrid method to estimate specific differential phase and rainfall with linear programming and physics constraints. IEEE Trans. Geosci. Remote Sens., 55(1), 96-111, https://doi.org/ 10.1109/TGRS.2016.2596295.

Huffman, G. J., R. F. Adler, D. T. Bolvin, G. Gu, E. J. Nelkin, K. P. Bowman, E. F. Stocker, and D. B. Wolff, 2007: The TRMM multi-satellite precipitation analysis: Quasi-global, multi-year, combined-sensor precipitation estimates at fine scale. Journal of Hydrometeorology, 8, 38-55.

Ice, R. L., A. K. Heck, J. G. Cunningham, and W. D. Zittel, 2014: Challenges of polarimetric weather radar calibration. Proc. 8th European Conference on Radar in Meteorology and Hydrology, Germany, Garmisch-Partenkirchen.

Jameson, A. R., 1991: Polarization radar measurements in rain at 5 and 9 GHz. J. Appl. Meteor., 30, 1500-1513, https://doi.org/ 10.1175/1520-0450(1991)030<1500:PRMIRA > 2.0.CO;2.

Johnson, M., Y. Jung, D. T. Dawson II, and M. Xue, 2016: Comparison of simulated polarimetric signatures in idealized supercell storms using two-moment bulk microphysics schemes in WRF. Mon. Wea. Rev., 144, 971-996, https://doi.org/ 10.1175/MWR-D-15-0233.1.

Jordan, R. L., B. L. Huneycutt, and M. Werner, 1995: The SIR-C/ X-SAR synthetic aperture radar system. IEEE Trans. Geosci. Remote Sens., 33(4), 829-839, https://doi.org/10.1109/36. 406669.

Jung, Y., G. F. Zhang, and M. Xue, 2008a: Assimilation of simulated polarimetric radar data for a convective storm using the ensemble Kalman filter. Part I: Observation operators for reflectivity and polarimetric variables. Mon. Wea. Rev., 136(6), 2228-2245, https://doi.org/10.1175/2007MWR2083.1.

Jung, Y., M. Xue, G. F. Zhang, and J. M. Straka, 2008b: Assimilation of simulated polarimetric radar data for a convective storm using the ensemble Kalman filter. Part II: Impact of polarimetric data on storm analysis. Mon. Wea. Rev., 136(6), 2246-2260, https://doi.org/10.1175/2007MWR2288.1.

Jung, Y., M. Xue, and G. F. Zhang, 2010: Simulations of polarimetric radar signatures of a supercell storm using a twomoment bulk microphysics scheme. Journal of Applied Meteorology and Climatology, 49(1), 146-163, https://doi.org/ 10.1175/2009JAMC2178.1.

Jung, Y., M. Xue, and M. J. Tong, 2012: Ensemble Kalman filter analyses of the 29-30 may 2004 Oklahoma Tornadic thunderstorm using one- and two-moment bulk microphysics schemes, with verification against polarimetric radar data. Mon. Wea. Rev., 140(5), 1457-1475, https://doi.org/10.1175/ MWR-D-11-00032.1.

Kalnay, E., 2003: Atmospheric Modeling, Data Assimilation and Predictability. Cambridge University Press, 368 pp.

Karimkashi, S., and G. F. Zhang, 2015: Optimizing radiation patterns of a cylindrical polarimetric phased-array radar for multimissions. IEEE Trans. Geosci. Remote Sens., 53, 2810 2818, https://doi.org/10.1109/TGRS.2014.2365362.

Khain, A. P., and Coauthors, 2015: Representation of microphysical processes in cloud-resolving models: Spectral (bin) microphysics versus bulk parameterization. Rev. Geophys., 53, 247-322, https://doi.org/10.1002/2014RG000468. 
Kumjian, M. R., 2013: Principles and applications of dualpolarization weather radar. Part 2: Warm and cold season applications. Journal of Operational Meteorology, 1(20), 243264, https://doi.org/10.15191/nwajom.2013.0120.

Kumjian, M. R., and A. V. Ryzhkov, 2008: Polarimetric signatures in supercell thunderstorms. Journal of Applied Meteorology and Climatology, 47, 1940-1961, https://doi.org/10.1175/ 2007JAMC1874.1.

Kumjian, M. R., A. P. Khain, N. Benmoshe, E. Ilotoviz, A. V. Ryzhkov, and V. T. J. Phillips, 2014: The anatomy and physics of $Z_{\mathrm{DR}}$ columns: Investigating a polarimetric radar signature with a spectral bin microphysical model. Journal of Applied Meteorology and Climatology, 53(7), 1820-1843, https://doi.org/10.1175/JAMC-D-13-0354.1.

Li, X. L., and J. R. Mecikalski, 2010: Assimilation of the dualpolarization Doppler radar data for a convective storm with a warm-rain radar forward operator. J. Geophys. Res., 115, D16208, https://doi.org/10.1029/2009JD013666.

Li, X. L., J. R. Mecikalski, and D. Posselt, 2017: An ice-phase microphysics forward model and preliminary results of polarimetric radar data assimilation. Mon. Wea. Rev., 145, 683708, https://doi.org/10.1175/MWR-D-16-0035.1.

Liu, H. P., and V. Chandrasekar, 2000: Classification of hydrometeors based on polarimetric radar measurements: Development of fuzzy logic and neuro-fuzzy systems, and in situ verification. J. Atmos. Oceanic Technol., 17, 140-164, https:// doi.org/10.1175/1520-0426(2000)017<0140:COHBOP $>2$.0. $\mathrm{CO} ; 2$.

Lorenc, A. C., 1986: Analysis methods for numerical weather prediction. Quart. J. Roy. Meteor. Soc., 112, 1177-1194, https:// doi.org/10.1002/qj.49711247414.

Mahale, V., G. Zhang, M. Xue, J. Gao, and H. D. Reeves, 2019: Variational retrieval of rain microphysics and related parameters from polarimetric radar data with a parameterized operator. J. Atmos. Oceanic Technol., in-review.

May, P. T., J. D. Kepert, and T. D. Keenan, 2008: Polarimetric radar observations of the persistently asymmetric structure of tropical cyclone Ingrid. Mon. Wea. Rev., 136(2), 616-630, https://doi.org/10.1175/2007MWR2077.1.

May, P. T., T. D. Keenan, D. S. Zrnić, L. D. Carey, and S. A. Rutledge, 1999: Polarimetric radar measurements of tropical rain at a 5-cm wavelength. J. Appl. Meteor., 38, 750-765, https:// doi.org/10.1175/1520-0450(1999)038<0750:PRMOTR >2.0. $\mathrm{CO} ; 2$.

Milbrandt, J. A., and M. K. Yau, 2005a: A multimoment bulk microphysics parameterization. Part I: Analysis of the role of the spectral shape parameter. J. Atmos. Sci., 62, 3051-3064, https://doi.org/10.1175/JAS3534.1.

Milbrandt, J. A., and M. K. Yau, 2005b. A multimoment bulk microphysics parameterization. Part II: A proposed threemoment closure and scheme description. J. Atmos. Sci., 62, 3065-3081, https://doi.org/10.1175/JAS3535.1.

Morrison, H., and J. Milbrandt, 2011: Comparison of two-moment bulk microphysics schemes in idealized supercell thunderstorm simulations. Mon. Wea. Rev., 139, 1103-1130, https:// doi.org/10.1175/2010MWR3433.1.

Morrison, H., G. Thompson, and V. Tatarskii, 2009: Impact of cloud microphysics on the development of trailing stratiform precipitation in a simulated squall line: Comparison of oneand two-moment schemes. Mon. Wea. Rev., 137, 991-1007, https://doi.org/10.1175/2008MWR2556.1.

Morrison, H., J. A. Curry, and V. I. Khvorostyanov, 2005: A new double-moment microphysics parameterization for application in cloud and climate models. Part I: Description. J. Atmos. Sci., 62, 1665-1677, https://doi.org/10.1175/JAS3446.1.

Ortega, K. L., J. M. Krause, and A. V Ryzhkov, 2016: Polarimetric radar characteristics of melting hail. Part III: Validation of the algorithm for hail size discrimination. Journal of Applied Meteorology and Climatology, 55, 829-848, https://doi. org/10.1175/JAMC-D-15-0203.1.

Overeem, A., H. Leijnse, and R. Uijlenhoet, 2013. Country-wide rainfall maps from cellular communication networks. Proc. Natl. Acad. Sci. USA, 110(8), 2741-2745, https://doi.org/ 10.1073/pnas.1217961110.

Park, H. S., A. V. Ryzhkov, D. S. Zrnić, and K.-E. Kim, 2009: The hydrometeor classification algorithm for the polarimetric WSR-88D: Description and application to an MCS. Wea. Forecasting, 24(3), 730-748, https://doi.org/10.1175/2008 WAF2222205.1.

Pfeifer, M., G. C. Craig, M. Hagen, and C. Keil, 2008: A polarimetric radar forward operator for model evaluation. Journal of Applied Meteorology and Climatology, 47(12), 32023220, https://doi.org/10.1175/2008JAMC1793.1.

Posselt, D. J., X. L. Li, S. A. Tushaus, and J. R. Mecikalski, 2015: Assimilation of dual-polarization radar observations in mixed- and ice-phase regions of convective storms: Information content and forward model errors. Mon. Wea. Rev., 143, 2611-2636, https://doi.org/10.1175/MWR-D-14-00347.1.

Putnam, B. J., M. Xue, Y. Jung, N. Snook, and G. F. Zhang, 2014: The analysis and prediction of microphysical states and polarimetric radar variables in a mesoscale convective system using double-moment microphysics, multinetwork radar data, and the ensemble Kalman filter. Mon. Wea. Rev., 142(1), 141162, https://doi.org/10.1175/MWR-D-13-00042.1.

Putnam, B. J., M. Xue, Y. Jung, G. F. Zhang, and F. Y. Kong, 2017b: Simulation of polarimetric radar variables from 2013 CAPS spring experiment storm-scale ensemble forecasts and evaluation of microphysics schemes. Mon. Wea. Rev., 145, 49-73, https://doi.org/10.1175/MWR-D-15-0415.1.

Putnam, B. J., M. Xue, Y. Jung, N. A. Snook, and G. F. Zhang, 2017a: Ensemble probabilistic prediction of a mesoscale convective system and associated polarimetric radar variables using single-moment and double-moment microphysics schemes and EnKF radar data assimilation. Mon. Wea. Rev., 145, 2257-2279, https://doi.org/10.1175/MWR-D-160162.1 .

Putnam, B. J., M. Xue, Y. Jung, N. A. Snook, and G. Zhang, 2019: EnKF assimilation of polarimetric radar observations for the 20 may 2013 Oklahoma Tornadic Supercell case. Mon. Wea Rev. (in press)

Rauber, R. M., and Coauthors, 2007: Rain in shallow cumulus over the ocean: The Rico campaign. Bull. Amer. Meteor. Soc., 88, 1912-1928, https://doi.org/10.1175/BAMS-88-12-1912.

Reeves, H. D., 2016: The uncertainty of precipitation-type observations and its effect on the validation of forecast precipitation type. Wea. Forecasting, 31, 1961-1971, https://doi.org/ 10.1175/WAF-D-16-0068.1.

Reeves, H. D., K. L. Elmore, A. Ryzhkov, T. Schuur, and J. Krause, 2014: Sources of uncertainty in precipitation-type forecasting. Wea. Forecasting, 29, 936-953, https://doi.org/10.1175/ WAF-D-14-00007.1.

Rodgers, C. D., 2000: Inverse Methods for Atmospheric Sounding: Theory and Practice. World Scientific Press, 258 pp.

Romine, G. S., D. W. Burgess, and R. B. Wilhelmson, 2008: A 
dual-polarization-radar-based assessment of the 8 May 2003 Oklahoma City area tornadic supercell. Mon. Wea. Rev., 136, 2849-2870, https://doi.org/10.1175/2008MWR2330.1.

Ryzhkov, A., and D. Zrnić, 1996. Assessment of rainfall measurement that uses specific differential phase. J. Appl. Meteor., 35, 2080-2090, https://doi.org/10.1175/1520-0450(1996)035 $<2080$ :AORMTU>2.0.CO;2.

Ryzhkov, A., M. Pinsky, A. Pokrovsky, and A. Khain, 2011: Polarimetric radar observation operator for a cloud model with spectral microphysics. Journal of Applied Meteorology and Climatology, 50(4), 873-894, https://doi.org/10.1175/2010 JAMC2363.1.

Ryzhkov, A., M. Diederich, P. F. Zhang, and C. Simmer, 2014: Potential utilization of specific attenuation for rainfall estimation, mitigation of partial beam blockage, and radar networking. J. Atmos. Oceanic Technol., 31, 599-619, https://doi.org/ 10.1175/JTECH-D-13-00038.1.

Ryzhkov, A. V., and D. S. Zrnić, 1995. Comparison of dualpolarization radar estimators of rain. J. Atmos. Oceanic Technol., 12, 249-256, https://doi.org/10.1175/1520-0426(1995) 012<0249:CODPRE $>2.0$. CO;2.

Ryzhkov, A. V., T. J. Schuur, D. W. Burgess, and D. S. Zrnic, 2005: Polarimetric tornado detection. J. Appl. Meteor., 44, 557-570, https://doi.org/10.1175/JAM2235.1.

Ryzhkov, A. V., M. R. Kumjian, S. M. Ganson, and A. P. Khain, 2013a: Polarimetric radar characteristics of melting hail. Part I: Theoretical simulations using spectral microphysical modeling. Journal of Applied Meteorology and Climatology, 52(12), 2849-2870, https://doi.org/10.1175/JAMC-D13-073.1.

Ryzhkov, A. V., M. R. Kumjian, S. M. Ganson, and P. F. Zhang, 2013b: Polarimetric radar characteristics of melting hail. Part II: Practical implications. Journal of Applied Meteorology and Climatology, 52(12), 2871-2886, https://doi.org/ 10.1175/JAMC-D-13-074.1.

Sachidananda, M., and D. S. Zrnić, 1987: Rain rate estimates from differential polarization measurements. J. Atmos. Oceanic Technol., 4, 588-598, https://doi.org/10.1175/15200426(1987)004<0588:RREFDP>2.0.CO;2.

Saeidi-Manesh, H., M. Mirmozafari, and G. Zhang, 2017: Low cross-polarisation high-isolation frequency scanning aperture coupled microstrip patch antenna array with matched dualpolarisation radiation patterns. Electronics Letters, 53(14), 901-902, https://doi.org/10.1049/el.2017.1282.

Seliga, T. A., and V. N. Bringi, 1976: Potential use of radar differential reflectivity measurements at orthogonal polarizations for measuring precipitation. J. Appl. Meteor., 15, 69-76, https://doi.org/10.1175/1520-0450(1976)015<0069: PUORDR $>2.0 . \mathrm{CO} ; 2$.

Seliga, T. A., V. N. Bringi, and H. H. Al-Khatib, 1979: Differential reflectivity measurements in rain: First experiments. IEEE Transactions on Geoscience Electronics, 17, 240-244, https:// doi.org/10.1109/TGE.1979.294652.

Snook, N., Y. Jung, J. Brotzge, B. Putnam, and M. Xue, 2016: Prediction and ensemble forecast verification of hail in the supercell storms of 20 May 2013. Wea. Forecasting, 31, 811-825, https://doi.org/10.1175/WAF-D-15-0152.1.

Snyder, J. C., A. V. Ryzhkov, M. R. Kumjian, A. P. Khain, and J. Picca, 2015: A $Z_{\mathrm{DR}}$ column detection algorithm to examine convective storm updrafts. Wea. Forecasting, 30(6), 18191844, https://doi.org/10.1175/WAF-D-15-0068.1.

Stailey J. E., and K. D. Hondl, 2016: Multifunction phased array radar for aircraft and weather surveillance. Proceedings of the IEEE, 104(3), 649-659, https://doi.org/10.1109/JPROC. 2015.2491179.

Straka, J. M., 1996: Hydrometeor fields in a supercell storm as deduced from dual-polarization radar. Preprints, 18th Conf. on Severe Local Storms, San Francisco, CA, Amer. Meteor. Soc., 551-554.

Straka, J. M., and D. S. Zrnić, 1993: An algorithm to deduce hydrometeor types and contents from multiparameter radar data. Preprints, 26th Int. Conf. on Radar Meteorology, Norman, OK, Amer. Meteor. Soc., 513-515.

Straka, J. M., D. S. Zrnić, and A. V. Ryzhkov, 2000: Bulk hydrometeor classification and quantification using polarimetric radar data: Synthesis of relations. J. Appl. Meteor., 39, 1341-1372, https://doi.org/10.1175/1520-0450(2000)039 $<1341$ :BHCAQU > 2.0.CO;2.

Sun, J. Z., and A. N. Crook, 1997: Dynamical and microphysical retrieval from doppler radar observations using a cloud model and its adjoint. Part I: Model development and simulated data experiments. J. Atmos. Sci., 54(12), 1642-1661, https://doi. org/10.1175/1520-0469(1997)054<1642:DAMRFD>2.0.CO; 2.

Sun, J. Z., and N. A. Crook, 1998: Dynamical and microphysical retrieval from Doppler radar observations using a cloud model and its adjoint. Part II: Retrieval experiments of an observed Florida convective storm. J. Atmos. Sci., 55(5), 835-852, https://doi.org/10.1175/1520-0469(1998)055<0835: DAMRFD $>2.0 . \mathrm{CO} ; 2$.

Ulbrich, C. W., and D. Atlas, 1984: Assessment of the contribution of differential polarization to improved rainfall measurements. Radio Sci., 19(1), 49-57, https://doi.org/10.1029/ RS019i001p00049.

Van Den Broeke, M. S., and S. T. Jauernic, 2014: Spatial and temporal characteristics of polarimetric tornadic debris signatures Journal of Applied Meteorology and Climatology, 53, 2217 2231, https://doi.org/10.1175/JAMC-D-14-0094.1.

Vivekanandan, J., D. S. Zrnic, S. M. Ellis, R. Oye, A. V. Ryzhkov, and J. Straka, 1999: Cloud microphysics retrieval using S-band dual-polarization radar measurements. Bull. Amer. Meteor. Soc., 80(3), 381-388, https://doi.org/10.1175/15200477(1999)080<0381:CMRUSB>2.0.CO;2.

Vivekanandan, J., W. M. Adams, and V. N. Bringi, 1991: Rigorous approach to polarimetric radar modeling of hydrometeor orientation distributions. J. Appl. Meteor., 30, 1053-1063, https://doi.org/10.1175/1520-0450(1991)030 $<$ 1053:RATPRM>2.0.CO;2.

Waterman, P. C., 1965: Matrix formulation of electromagnetic scattering. Proceedings of the IEEE, 53, 805-812, https://doi. org/10.1109/PROC.1965.4058.

Weber, M. E., J. Y. N. Cho, J. S. Herd, J. M. Flavin, W. E. Benner, and G. S. Torok, 2007: The next-generation multimission U.S. surveillance radar network. Bull. Amer. Meteor. Soc., 88, 1739-1752, https://doi.org/10.1175/BAMS-88-11-1739.

Wen, G., A. Protat, P. T. May, X. Z. Wang, and W. Moran, 2015: Cluster-based method for hydrometeor classification using polarimetric variables. Part I: Interpretation and analysis. J. Atmos. Oceanic Technol., 32, 1320-1340, https://doi.org/ 10.1175/JTECH-D-13-00178.1.

Wen, G., A. Protat, P. T. May, W. Moran, and M. Dixon, 2016: Cluster-based method for hydrometeor classification using polarimetric variables. Part II: Classification. $J$. Atmos. Oceanic Technol., 33, 45-60, https://doi.org/10.1175/ 
JTECH-D-14-00084.1.

Wheatley, D. M., N. Yussouf, and D. J. Stensrud, 2014: Ensemble Kalman filter analyses and forecasts of a severe mesoscale convective system using different choices of microphysics schemes. Mon. Wea. Rev., 142, 3243-3263, https://doi.org/ 10.1175/MWR-D-13-00260.1.

Wu, B., J. Verlinde, and J. Z. Sun, 2000: Dynamical and microphysical retrievals from doppler radar observations of a deep convective cloud. J. Atmos. Sci., 57(2), 262-283, https://doi. org/10.1175/1520-0469(2000)057<0262:DAMRFD>2.0.CO; 2 .

Yoshikawa, E., V. Chandrasekar, and T. Ushio, 2014. Raindrop size distribution (DSD) retrieval for X-band dualpolarization radar. J. Atmos. Oceanic Technol., 31(2), 387403, https://doi.org/10.1175/JTECH-D-12-00248.1.

Yussouf, N., and D. J. Stensrud, 2010: Impact of phased-array radar observations over a short assimilation period: $\mathrm{Ob}-$ serving system simulation experiments using an ensemble Kalman filter. Mon. Wea. Rev., 138, 517-538, https://doi.org/ 10.1175/2009MWR2925.1.

Yussouf, N., D. C. Dowell, L. J. Wicker, K. H. Knopfmeier, and D. M. Wheatley, 2015: Storm-scale data assimilation and ensemble forecasts for the 27 April 2011 severe weather outbreak in Alabama. Mon. Wea. Rev., 143, 3044-3066, https:// doi.org/10.1175/MWR-D-14-00268.1.

Yussouf, N., E. R. Mansell, L. J. Wicker, D. M. Wheatley, and D. J. Stensrud, 2013: The ensemble Kalman filter analyses and forecasts of the 8 May 2003 Oklahoma city tornadic supercell storm using single- and double-moment microphysics schemes. Mon. Wea. Rev., 141, 3388-3412, https://doi.org/ 10.1175/MWR-D-12-00237.1.

Zhang, G. F., 2016: Weather Radar Polarimetry. CRC Press, 304 pp.

Zhang, G. F., J. Z. Sun, and E. A. Brandes, 2006: Improving parameterization of rain microphysics with disdrometer and radar observations. J. Atmos. Sci., 63, 1273-1290, https://doi. org/10.1175/JAS3680.1.

Zhang, G. F., R. J. Doviak, D. S. Zrnic, J. Crain, D. Staiman, and Y. Al-Rashid, 2009: Phased array radar polarimetry for weather sensing: A theoretical formulation for bias corrections. IEEE Trans. Geosci. Remote Sens., 47, 3679-3689, https://doi.org/10.1109/TGRS.2009.2029332.

Zhang, G. F., R. J. Doviak, D. S. Zrnić, R. Palmer, L. Lei, and Y. Al-Rashid, 2011: Polarimetric phased-array radar for weather measurement: A planar or cylindrical configuration? J. Atmos. Oceanic Technol., 28, 63-73, https://doi.org/10.1175/ 2010JTECHA1470.1.

Zhang, J., and Coauthors, 2016: Multi-radar multi-sensor (MRMS) quantitative precipitation estimation: Initial operating capabilities. Bull. Amer. Meteor. Soc., 97, 621-638, https://doi.org/ 10.1175/BAMS-D-14-00174.1.

Zhang, J., and Coauthors, 2017: MRMS dual-polarization radar synthetic QPE. Proc. 38th Conf. Radar Meteorology, $28 \mathrm{Au}-$ gust -1 September 2017, Chicago, AMS.

Zrnic, D. S., and K. Aydin, 1992: Polarimetric signatures of precipitation. Applied Computational Electromagnetics Society (ACES) Newsletter, 7(2), 12-14.

Zrnic, D. S., and A. V. Ryzhkov, 1999: Polarimetry for weather surveillance radars. Bull. Amer. Meteor. Soc., 80, 389-406, https://doi.org/10.1175/1520-0477(1999)080<0389:PFWSR> 2.0.CO;2.

Zrnic, D. S., V. M. Melnikov, and J. K. Carter, 2006: Calibrating differential reflectivity on the WSR-88D. J. Atmos. Oceanic Technol., 23, 944-951, https://doi.org/10.1175/ JTECH1893.1.

Zrnic, D. S., and Coauthors, 2007: Agile-beam phased array radar for weather observations. Bull. Amer. Meteor. Soc., 88, 1753 1766, https://doi.org/10.1175/BAMS-88-11-1753. 